\title{
The Historical Significance of the Geometric Designs in the Northeast Dome Chamber of the Friday Mosque at Isfahan
}

\author{
Jay Francis Bonner ${ }^{1}$
}

Published online: 4 November 2015

(C) Kim Williams Books, Turin 2015

\begin{abstract}
Surviving architectural monuments provide the primary source for understanding the historical development of Islamic geometric design. The early Islamic architecture of Khurasan and eastern Persia establishes the Samanids, Qarakhanids, Ghaznavids, Ghurids and Seljuks as principle contributors in the maturation of the geometric ornamental tradition. The collective architectural legacy of these cultures reveals the significance of their contribution to our knowledge of Islamic geometric design. However, no individual monument surpasses the historical importance of the northeast dome chamber of the Friday Mosque at Isfahan. New research indicates that many of the geometric designs employed within this chamber are the earliest examples of their ornamental variety. What is more, these patterns represent a methodological breakthrough in the application of the polygonal technique of pattern generation, thereby facilitating ever-greater stylistic and geometric innovation.
\end{abstract}

\section{Introduction}

The precise origins of Islamic geometric star patterns are impossible to establish categorically. There are too many ornamental influences, and too few remaining buildings and objects of art from the early formative period to know definitively when or precisely how this intrinsically Islamic ornamental convention began. The use of stars as a decorative motif was practiced by the pre-Islamic cultures of Byzantium, Coptic Egypt and Sassanid Persia, and included their use as either individual motifs within a decorative schema or as constellations wherein multiple

Jay Francis Bonner jay.bonner@gmail.com;

http://www.bonner-design.com

115 Avenida Casa del Oro, Santa Fe, NM 87508, USA

Birkhäuser 
stars provide the primary character of the design. The Umayyads of the seventh and eighth centuries readily co-opted the geometric aesthetic conventions of their conquered subjects. While the geometric ornament of the Umayyads is derivative of earlier examples, the primary difference between pre-Islamic patterns with multiple stars, as found in some of the Hellenic mosaic pavements, and those subsequently developed under Umayyad patronage is in the cohesiveness of the overall design. In the earlier Hellenic work, the stars are independent elements scattered across the plane in a regulated staccato fashion, relating to one another through geometric proximity and similitude. By contrast, within the Islamic star pattern aesthetic, the points of each star proceed outward to join with the similarly extended lines from adjacent stars to produce an interconnected network wherein each star is an integral part of a unified whole.

A frequent addition to the geometric design itself is the interweaving treatment of the widened pattern lines. This practice was also prevalent in the ornament of the Byzantines, Copts and Sassanids, and similarly applied to the emerging Umayyad geometric style. Examples of this new geometric aesthetic are exemplified in the Umayyad window grilles at both the Great Mosque of Damascus (c. 715) and the Qasr al-Hayr al-Gharbi near Palmyra, Syria (724-27). While these early Umayyad examples are geometrically simple compared to the Islamic geometric patterns developed in subsequent centuries, they were stylistically foundational to the establishment of the Islamic geometric aesthetic that followed.

The Abbasid successors of the Umayyads were particularly important in cultivating the geometric arts. The history of Islamic geometric star patterns can be regarded as a sequential evolution from simplicity to complexity. From its onset in the ninth and tenth centuries, this new form of ornament was characterized by an overall geometric matrix with primary stars or regular polygons located upon the vertices of a repetitive grid. The geometric star patterns from this early period have either 3-fold or 4-fold symmetry: the former characterized by hexagons or sixpointed stars located on the vertices of either a triangular or hexagonal repeat unit; and the latter generally characterized by 8-pointed stars, octagons or squares placed on the vertices of a square repeat unit. Geometrically simplistic patterns of these varieties are found in several of the early monuments in the central and western regions of Abbasid influence, including the Great Mosque of Shibam Aqyan near Kawkaban in Yemen (pre-872), the mosque of ibn Tulun (876-79) in Fustat, Egypt (now part of greater Cairo), and the Baghdadi minbar (c. 856) at the Great Mosque of Kairouan in Tunisia.

However, it is in the eastern regions of Abbasid influence that the discipline of Islamic geometric pattern making appears to have benefited from the most innovative and influential artistic attention. The ruins of the No Gumbad mosque in Balkh, Afghanistan (800-850) are extensively ornamented with carved stucco geometric and floral designs. Among the many ornamental motifs is an example of the classic star-and-cross design with 8-pointed stars at each vertex of the orthogonal grid. It is significant that the use of this design at the No Gumbad mosque is contemporaneous with its use on the wooden minbar at the Great Mosque of Kairouan. Clearly, ninth-century Abbasid ornamental conventions disseminated quickly throughout their vast territories; helping to create an ornamental style that, 
while engendering distinct regional variations, nonetheless exhibited remarkable aesthetic cohesion. The No Gumbad mosque was built during the same approximate period as the floral examples found in excavations of the Bab al-"Amma (836-7) and the Bulawara Palace (849-59) in Samarra, Iraq. Both the floral infill of the geometric designs at the mosque of ibn Tulun in Egypt, and the carved stucco floral infill designs in the No Gumbad mosque have much in common with the Samarra style B floral designs; providing added evidence of the rapid dissemination of newly developed ornamental innovations throughout Abbasid territories. The ninthcentury incorporation of the Samarra floral conventions in regions as far flung as Cairo and Balkh, as well as the utilization of the star-and-cross pattern during the same period in both the east and west, strongly supports the argument for the centrality of Baghdad in this process of dissemination. However, the surviving architectural record strongly indicates that the early developmental innovations and maturation of Islamic geometric star patterns took place primarily in the eastern regions of Khurasan and eastern Persia and spread westward during the period of Seljuk expansion.

\section{Early Geometric Patterns in Khurasan and Eastern Persia}

Evidence for the growth toward full maturity of the Islamic geometric idiom primarily resides in multiple architectural monuments produced during the Samanid, Buyid, Qarakhanid, Ghaznavid, Ghurid and Seljuk dynasties in Khurasan and greater Persia. While some are unquestionably of greater significance to the history of geometric pattern, these tenth-, eleventh- and twelfth-century buildings collectively provide a historical record of the growth in sophistication within this ornamental tradition. Significant examples from the Samanid era include several finely carved stucco panels from the excavations of a private residence at Sabz Pushan outside Nishapur (c. 960-85) (Fig. 1), and the arch above the pishtaq of the mausoleum of Arab Ata (977-78) at Tim, Uzbekistan, $85 \mathrm{~km}$ southwest of Samarkand. Buyid examples include the Friday Mosque at Na'in, Iran (960), and although not architectural, an illuminated frontispiece from the celebrated Quran created by ibn al-Bawwab in Baghdad (1001). Qarakhanid sites with significant geometric designs include the Maghak-i Attari mosque in Bukhara, Uzbekistan (1178-79), and the three adjoining mausolea at Uzgen, Kyrgyzstan (constructed between 1012 and 1179) (Fig. 2). Ghaznavid monuments with significant geometric designs include the Lashkari Bazar near Bust, Afghanistan (early eleventh century) (Fig. 3), the minaret of Mas'ud III in Ghazna, Afghanistan (1099-1115), and the ruins of the Ribat-i Mahi Caravanserai near Mashhad, Iran (1019-20). Ghurid buildings with notable geometric designs include portions of the Lashgar Gah palace near Bust, Afghanistan (after 1149); the Taq-i Bust arch in Bust (1149) (Fig. 4); the western mausoleum at Chisht, Afghanistan (1167); the Shah-i Mashhad in Gargistan, Afghanistan (1176); the Friday Mosque at Herat, Afghanistan (1200); and the minaret of Jam in the remote mountains of central Afghanistan (1174-75 or 1194-95). The Seljuks were particularly prolific, and significant monuments include: the eastern tomb tower (1067) and the western tomb tower (1093-94) at Kharraqan in Qazvin Province, Iran; 


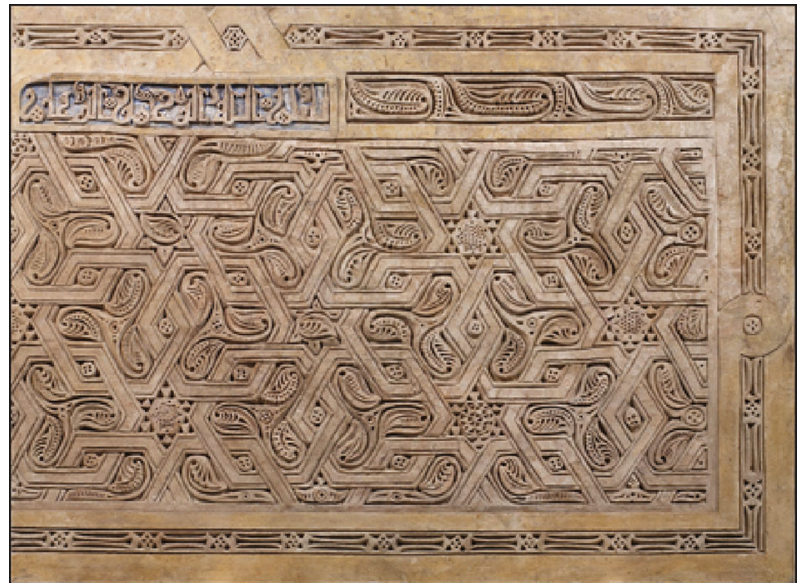

Fig. 1 Samanid era stucco panel from the Sabz Pushan archaeological site outside Nishapur, Iran

Fig. 2 Qarakhanid brickwork ornament from the three adjoining mausolea at Uzgen, Kyrgyzstan

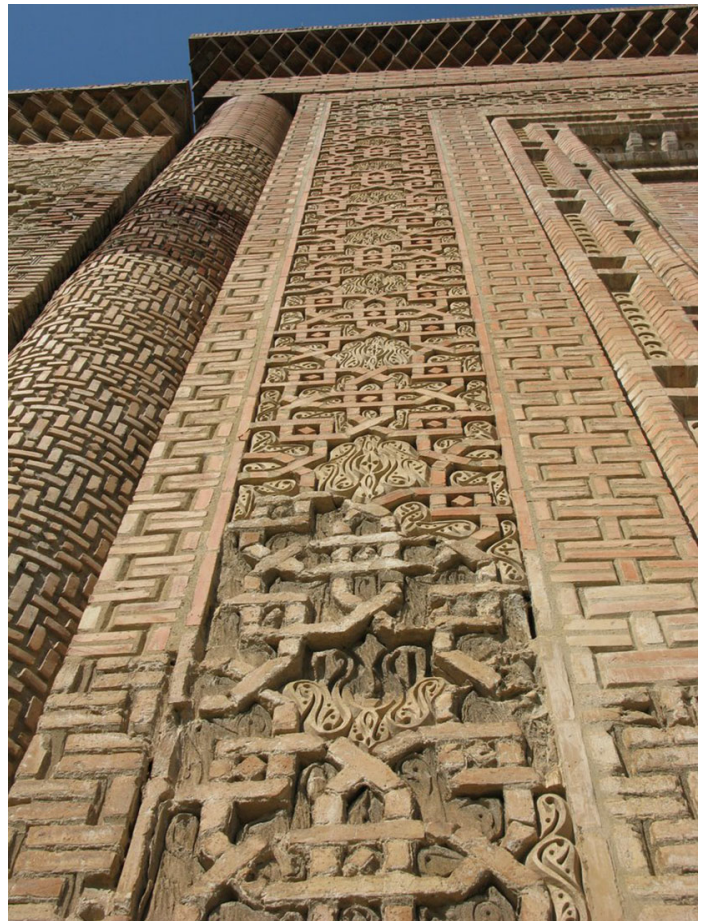

the Friday Mosque at Abyaneh, Iran (1073); the Friday Mosque at Damghan, Iran (1080); the Khwaja Atabek mausoleum in Kerman (1100-1150); the Friday Mosque in Barsian, near Isfahan (1105); the Friday Mosque of Golpayegan, Iran (1105-18); the minaret of Daulatabad outside Balkh, Afghanistan (1108-09) (Fig. 5); the Friday 


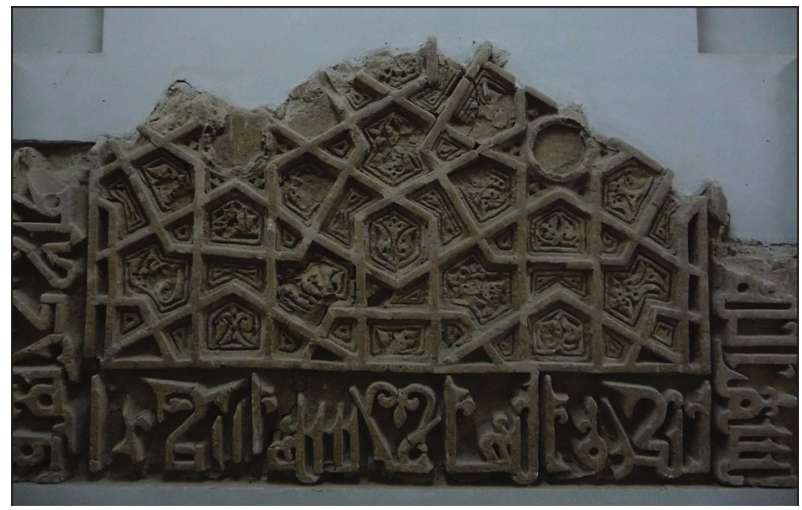

Fig. 3 Ghaznavid stucco panel from the Lashkari Bazar near Bust, Afghanistan

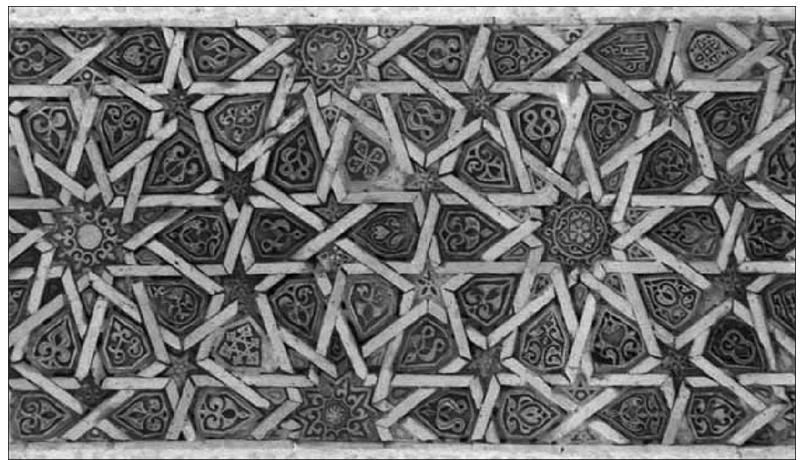

Fig. 4 Ghurid brickwork ornament from the intrados of the Taq-i Bust arch in Bust, Afghanistan

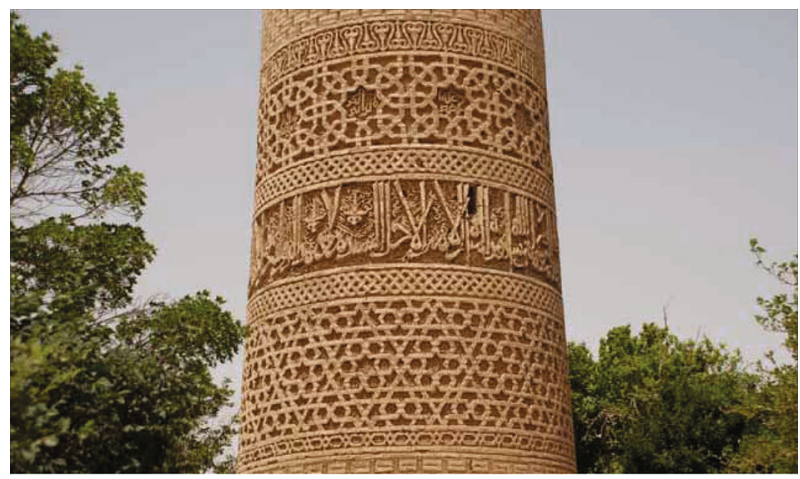

Fig. 5 Seljuk brickwork ornament from the minaret of Daulatabad outside Balkh, Afghanistan 


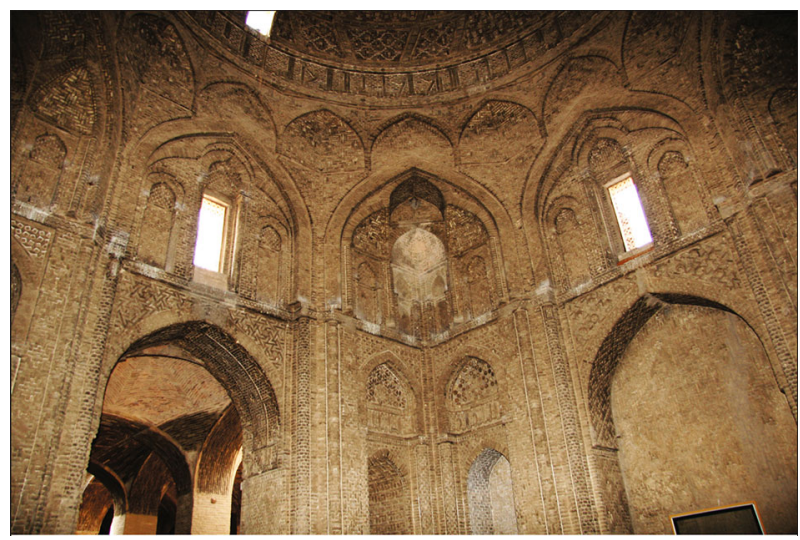

Fig. 6 Recessed arches in the lower portion of the walls of the Seljuk northeast dome chamber in the Friday Mosque at Isfahan

Mosque at Sin in Iran (1134); the Seh Gunbad in Orumiyeh, Iran (1180); the Mu'mine Khatun mausoleum in Nakhichevan, Azerbaijan (1186) - constructed by the Ildegizid atabegs of the Seljuks; the Gunbad-i Qabud in Maragha, Iran (1196-97); the Friday Mosque at Forumad, Iran (twelfth century); and the Gunbad-i 'Alaviyan in Hamadan, Iran (late twelfth century).

Throughout these many examples of Islamic geometric pattern are a wide diversity of geometric schema and repetitive devices, characterized by ever evolving complexity. It was during this period that the polygonal technique became the preeminent method of constructing geometric patterns, that the four standard pattern families were established as fundamental components of this traditions, and that the practices used for creating geometric designs were expanded to include both systematic and non-systematic methodologies. However, for all the diversity and beauty of the multiple examples of geometric design found in the many pre-Mongol monuments of Khurasan and greater Persia, no building comes close in historical significance to that of the northeast dome chamber of the Friday Mosque at Isfahan (1088-89).

\section{Northeast Dome Chamber of the Friday Mosque at Isfahan}

The Friday Mosque at Isfahan is one of the great mosque complexes of Islamic antiquity. The foundation of the mosque dates to the eighth century, although the earliest extant portions of the building date to the eleventh century when Isfahan became the capitol of the Seljuk Empire. Over subsequent centuries the Friday Mosque at Isfahan received the ongoing patronage from the Il-khanid, Muzzaffarid, Aq Qoyunlu, Timurid and Safavid dynasties, and restoration continues to the present day. The earlier Seljuk portions of this mosque are characterized by the masterful use of ornamental brickwork. Indeed, this Seljuk construction is considered one of the most important examples of ornamental brickwork in the 
entire world; and in no portion of the Friday Mosque at Isfahan does the brickwork ornament exceed that of the northeast dome chamber (Fig. 6). In short, it is a jewel of this ornamental medium.

The northeast dome chamber can be regarded as the culmination of the rapid advances made in brickwork architecture by previous artists in Khurasan and greater Persia. This is especially germane in that these advances are intertwined with parallel advances in geometric design. Indeed, advances in the tradition of Islamic geometric patterns must be regarded in the context of the brickwork ornament of the eastern dynasties. The Persian term for this brickwork ornament is banna'i, or work of brick builders. ${ }^{1}$ The earliest examples of Islamic ornamental brickwork are found in present-day Iraq, and make use of very simple geometric motifs that rely upon the rectilinearity of the brick module. Among the earliest surviving examples are the Baghdad Gate in Raqqa (772) and the Court of Honor at the desert palace of Ukhaidir (c. 764-778), some 120 miles south of Baghdad. Both these examples employ simple brickwork designs such as chevrons and swastikas inside a series of horizontally aligned blind arches. Of particular interest is the minaret of Mujda (mid-eighth century), situated between the two Abbasid palaces of Ukhaidir and Atshan. While little of this minaret still stands, and while the geometric brickwork is very basic, it is remarkable for its conceptual similarity to the beautiful ornamental brick minarets produced by the Ghaznavids and Seljuks some 300 years later. In the eastern regions, the rise in sophistication of ornamental brickwork began with the Samanids and Buyids, and can be seen in such buildings as the Samanid mausoleum in Bukhara (c. 914-43) and the Jurjir mosque in Isfahan (976-85). The succeeding Ghaznavids, Ghurids and Seljuks were particularly innovative in their use of this medium. Artists working for each of these dynasties pioneered the application of brickwork ornament to Kufi calligraphy, muqarnas vaulting and geometric star patterns. Over time, and in the hands of master artists, the intertwining of brickwork and geometric design produced increasingly diverse and complex designs. What began as simple key patterns and interlocking devices that firmly adhered to the $90^{\circ}$ orthogonal angularity of the brick module was transformed into an ornamental medium with tremendous design flexibility. The repertoire of the brick artist was expanded to include cast ceramic inserts, often with either a glazed or unglazed decorative relief, as well as specially cut, or specially molded bricks that allowed them to break free of the orthogonal rigidity that otherwise constrained this medium. In this way, the rise in technical mastery of ornamental brickwork in Khurasan and Persia during the tenth, eleventh and twelfth centuries provided an ideal medium for the growth of complexity of geometric patterns with angles other than $90^{\circ}$. This was equally the case for the application of cursive scripts, increasingly elaborate forms of knotted and floriated Kufi scripts, and even the floral idiom.

Historians of Islamic and Persian architecture have long recognized the significance of the northeast dome chamber as one of the preeminent examples of Seljuk brickwork construction, for its magnificent proportions and for its perfectly resolved muqarnas vaulting. The beauty of the geometric pattern on the interior

\footnotetext{
1 The Persian terms hazarbaf and parceh are also used for brickwork ornament. It is interesting that both these terms are also associated with the woven rush matting and textile industries (Wulff 1966).
} 
surface of the dome is widely acknowledged for its early date, exceptional beauty and unusual 5-fold rotational symmetry. However, what has remained virtually unrecognized is the exceptional historic significance of the geometric patterns that also adorn this architectural space. Of particular importance are the first known occurrences of several varieties of geometric design central to this artistic tradition. Furthermore, the geometric patterns in the northeast dome chamber collectively indicate that this building represents a significant milestone in the historical development of the polygonal technique; the preeminent design methodology used by Muslim geometric artists throughout the Islamic world.

\section{Design Methodology: the Polygonal Technique}

Several techniques were used historically for generating Islamic geometric patterns. Many of the less complex geometric designs can be created from more than one methodological approach. Among the more basic patterns it is therefore not always possible to know for certain which generative technique was used. While almost all of the early geometric patterns known to the historical record are easily produced with the polygonal technique (sometimes referred to as polygons in contact, or PIC), these can frequently also be produced with alternative methodologies, such as connecting points upon either an isometric or orthogonal grid, simply assembling predetermined pattern elements such as 8-pointed stars, or through connecting points upon a simple repetitive geometric construction (Bonner 2016). Fig. 7 demonstrates three methods for constructing the same basic 4-fold pattern. Figure 7a shows the 'grid method' for constructing this well-known 4-fold pattern. Unlike patterns created from the isometric grid, designs derived from the orthogonal grid almost always require geometric adjustment to achieve the correct proportions. This is especially evident when making designs that have 8-pointed stars, and this discrepancy is indicated in the proportional differences between this example and that of its neighbors. Figure $7 \mathrm{~b}$ demonstrates the production of the same design, but with correct proportions, by using the 'point-joining' method. This places an initial

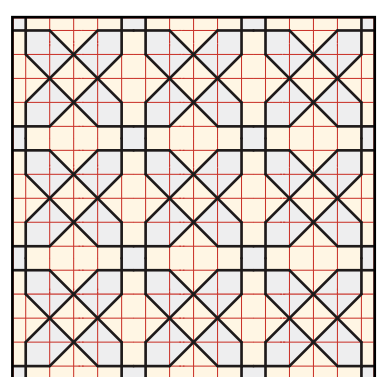

(a)

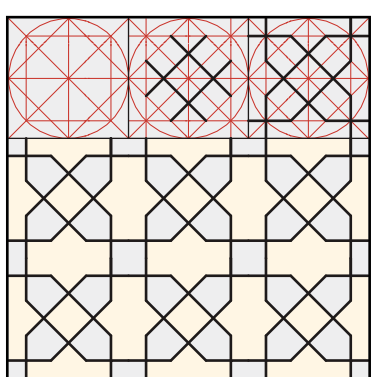

(b)

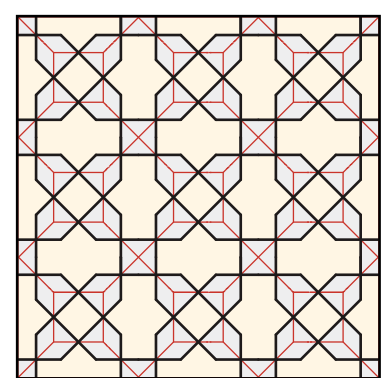

(c)

Fig. 7 Three methods for constructing the same 4-fold pattern: a the grid method; b point-joining; and c the polygonal technique 
geometric construction within a square repeat and builds upon this to create the completed design. There is a small amount of evidence that this methodology was used historically. A limitation of this methodology is its inability to create the large volume of highly complex geometric designs associated with this ornamental tradition. Figure 7c illustrates how this pattern can also be produced from an underlying tessellation of hexagons and squares (white lines). The proportion of each hexagon is simply a collapsed regular octagon. The fact that the polygonal technique is a more demanding design methodology requiring two distinct steps would appear to argue for the greater relevance of less complicated and more immediate methodologies such as those mentioned above. However, the strength of the polygonal technique is in its inherent flexibility, providing for the creation of the high level of design diversity and range of complexity that characterizes this tradition. By the close of the eleventh century geometric patterns were being created with significantly greater complexity. These would have been very difficult to produce using anything other than the polygonal technique. In this way, the polygonal technique became the primary force behind the ongoing growth in the sophistication of Islamic geometric star patterns that took place following the onset of this tradition beginning in the eighth and ninth centuries, through its period of gradual maturation during the tenth, eleventh and twelfth centuries, and into the period of full maturity during the thirteenth and fourteenth centuries. Of all the identified design methodologies that produce acceptable Islamic geometric patterns, only the polygonal technique has multiple examples of evidence to support its unquestionable historicity. ${ }^{2}$ These include pattern scrolls and ancient treatises such as the Topkapi scroll (Necipoğlu 1995) ${ }^{3}$ and the anonymous Persian treatise at the Bibliothèque Nationale de France [Anonymous n.d.], scribed reference lines under the painting in Quranic illuminations, and multiple architectural panels where the generative structure is included within the completed design.

The distinctive feature of the polygonal technique is the employment of a polygonal tessellation that acts as a substructure from which the geometric pattern is derived. This process involves the placement of the pattern lines upon specified points along the edges of each polygon within a given underlying generative tessellation. After the full set of applied pattern lines is complete, the underlying generative tessellation is discarded, leaving behind only the derived pattern-with no easily discernable indication for how the pattern was constructed. By the twelfth century, four distinct varieties of geometric pattern had evolved. The visual quality of each of these pattern families is the direct result in how the lines of a given pattern are applied to the underlying generative tessellation. Figure 8 illustrates how three of these are determined by placing crossing pattern lines that intersect on or near the midpoints of the underlying polygonal edges. The specific contact angle of these crossing pattern lines determines the overall character of the design. For purposes of descriptive clarity these three families are referred to as acute, median

\footnotetext{
2 The historical evidence for the polygonal technique is examined in great detail in the author's forthcoming book on Islamic geometric patterns (Bonner 2016).

3 The Topkapi scroll has a very wide diversity of both systematic and non-systematic patterns, represented with their underlying generative tessellation.
} 


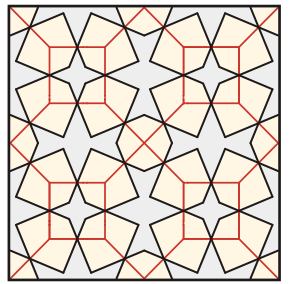

acute

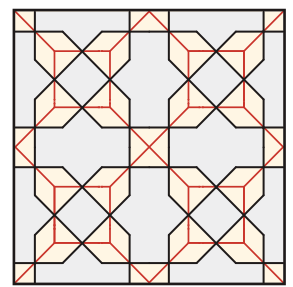

median

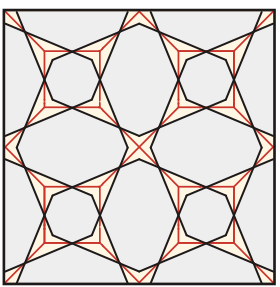

obtuse

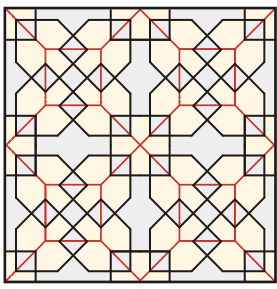

2-point

Fig. 8 The four standard pattern families as applied to the same underlying generative tessellation as used in Fig. 7c

and obtuse. The fourth historically common pattern family places the pattern lines upon two points of each underlying polygonal edge, and is hence referred to as the 2-point family. These two contact points are typically determined by dividing the polygonal edges into either equal thirds or quarters. Any one of the four pattern families can be used when extracting a geometric pattern from an underlying polygonal tessellation. The fact that each underlying formative tessellation can generate patterns from each family significantly augments the generative design potential of this methodology. It is worth noting that each of the four examples in Fig. 8 is created from the same underlying tessellation as the median pattern in Fig. 7c. This demonstrates an important aspect of the polygonal technique: a single underlying tessellation will create multiple designs. In this way, the polygonal technique provides far greater design flexibility and diversity than any other constructive methodology.

\section{Systematic Design Methodology}

During the period of rising maturity, Muslim artists discovered several polygonal systems for creating geometric patterns. Each of these relies upon a limited set of polygonal modules, with associated pattern lines, that combine in edge-to-edge configurations to create underlying tessellations. The strength of systematic design methodologies is the ease of exploring new generative assemblages and their resulting patterns. If one considers that the modules that make up each system can be combined in innumerable ways, and that each of the four pattern families can be applied to each tessellation, there are an unlimited number of geometric patterns available to each system.

I have identified five design systems that were employed historically: the system of regular polygons, the 4-fold system $A$, the 4-fold system B, the 5-fold system and 
the 7-fold system. ${ }^{4}$ The patterns created from each of these have their own unique character in each of the four pattern families. It is worth noting that during the formative period of this design tradition, the application of the crossing pattern lines was not always standardized to a specific contact angle for a given pattern family within a specific generative system. Over time, the contact angles of applied pattern lines for each pattern family within each specific design system became more standardized. However, variations and exceptions to the conventions always remained a feature of this systematic methodology. Figure 9 illustrates two variations in pattern line allocation for the acute and median patterns created from the underlying tessellation in Fig. 8. Figure 9a is a Ghaznavid design from the Ribat-i Mahi near Mashhad (1019-20). This employs the same acute pattern lines that create the distinctive octagons within the pattern matrix, but differs in its incorporation of two sets of arbitrary parallel pattern lines that penetrate the underlying square elements. These are not fixed upon the midpoints of the underlying polygonal edges. Figure $9 \mathrm{~b}$ is a pattern that arbitrarily extends selected pattern lines from the standard median design in Fig. 8. This creates a network of parallel diagonal lines within the superimposed octagons. This design was used by Qara Qoyunlu artists at the Great Mosque of Van in Eastern Turkey (1389-1400). The design in Fig. 9c is comprised of superimposed dodecagons, each centered upon a vertex where four hexagons meet. The scale of the dodecagons is conveniently determined by the midpoints of the underlying polygonal edges. This is a Qarakhanid design from the entry of the Maghak-i Attari Mosque in Bukhara (1178-79). These three examples demonstrate the artistic license that was frequently employed when using the polygonal technique. Variations such as these are especially common among patterns created during the formative period when the standardization of the four pattern families had not yet become fully codified.

\footnotetext{
${ }^{4}$ Other authors have demonstrated the correlation between specific geometric designs and their underlying generative tessellation. The first to publish examples of the polygonal technique was Ernest $\mathrm{H}$. Hankin, although he never gave the methodology a name. However, while Hankin's excellent work includes many examples that can work systematically, he did not identify the systematic potential of the modules within his illustrations or text (Hankin 1905, 1925a, b, 1934, 1936). Emil Makovicky illustrated the relationship between underlying tessellations comprised of regular pentagons, barrel hexagons, rhombi and decagons and the similarity of the created patterns in the Maghreb and Persia to Penrose quasiperiodic tilings (Makovicky 1992, 1998). The tessellating modules identified by Makovicky are a subset of the full 5-fold system identified later by myself (Bonner 2000; Bonner 2003). The system of regular polygons, the 4-fold system $A$, the 4-fold system $B$ and the 5-fold system, along with their associated pattern lines in each of the four pattern families, were first identified in my widely circulated unpublished manuscript (Bonner 2000), and except for the 4-fold system B, later described and illustrated in my Bridges paper on self-similar Islamic geometric design from the Maghreb and Persia (Bonner 2003). Together with Marc Pelletier, I first published on the 7-fold system in our two Bridges papers (Bonner and Pelletier 2012). Craig Kaplan has contributed significantly to the field of design methodology, especially as regards the application of computational algorithms to the polygonal technique for creating geometric star patterns. Kaplan's work focuses upon both systematic and nonsystematic designs (Kaplan 2002, 2004, 2005). (Lu and Steinhardt 2007) identify only a subset of the modules that comprise the 5-fold system, and they limit their analysis to the associated pattern lines of just the median pattern family (with its characteristic $72^{\circ}$ crossing pattern lines at the midpoints of each polygonal edge). Peter Cromwell has developed his own systematic identifications that focus upon subset elements with specific pattern allocations that acknowledge and are placed in context with my prior work (Cromwell 2009, 2010, 2012). Reza Sarhangi has also published his research and analyses of several Persian patterns that are constructed with modules from the 5-fold system (Sarhangi 2012).
} 


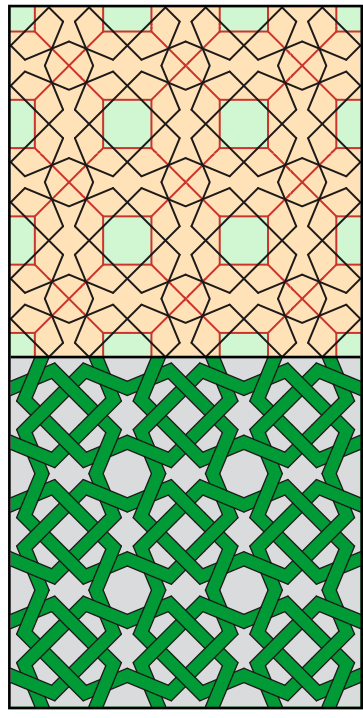

(a)

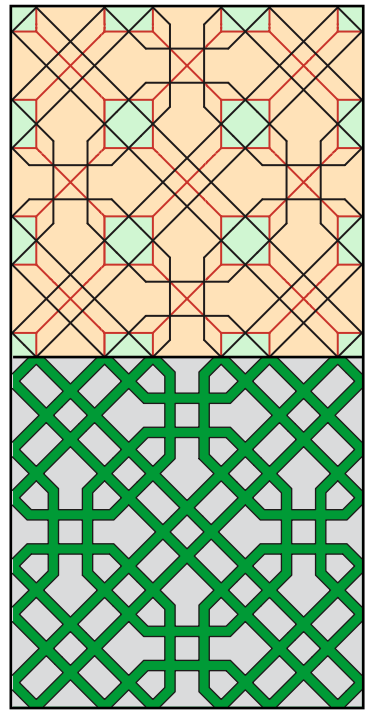

(b)

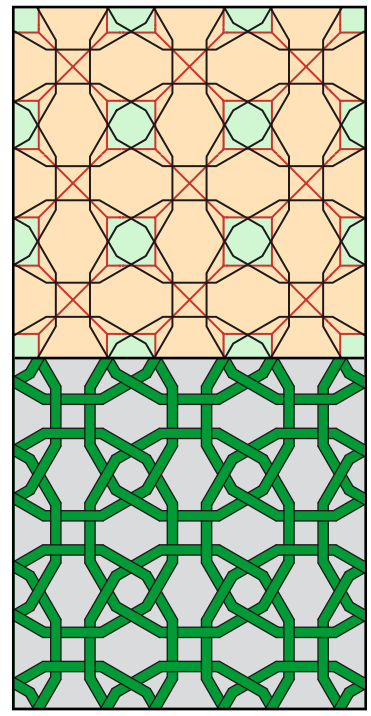

(c)

Fig. 9 Three non-standard patterns created from the same underlying tessellation as in Fig. 8

\section{The System of Regular Polygons}

The system of regular polygons was the earliest generative polygonal system to have developed. The construction of geometric patterns from underlying tessellations made up of regular polygons appears to have begun in the ninth century and continued throughout the length and breadth of this ornamental tradition. The argument for the early use of the polygonal technique is supported by the employment by Muslim artists of polygonal tessellations as decorative motifs from as early as the eighth century. Noteworthy among the diverse locations of this early form of Islamic geometric ornament include: the wooden ceilings of the Great Mosque of Sana' a in Yemen (70515); the portal of the palace of Qasr al-Hayr al-Gharbi near Palmyra, Syria (724-27); ${ }^{5}$ the No Gumbad mosque in Balkh, Afghanistan (800-850); the Bab al-'Amma (836-7) and the Bulawara Palace (849-59) in Samarra, Iraq; the Yu'firid ceiling panels of the Great Mosque of Shibam Aqyan near Kawkaban in Yemen (pre-872); and the ibn Tulun mosque in Cairo (876-79). Considering the general interest in polygonal tessellations as ornament, it is entirely reasonable to allow for the inventive leap from using such tessellations as ornamental motifs to employing them as a substratum upon which pattern lines were then applied. The precise date for the methodological discovery of using underlying tessellations to create geometric patterns is ambiguous. This is due to the aforementioned fact that the simplicity of ninth- and tenth-century examples allows for their creation with either the polygonal technique, the iterative placements of simple star forms, or simply through the tracing of lines from the

\footnotetext{
5 The portal of the palace of Qasr al-Hayr al-Gharbi is now in the National Museum of Damascus.
} 


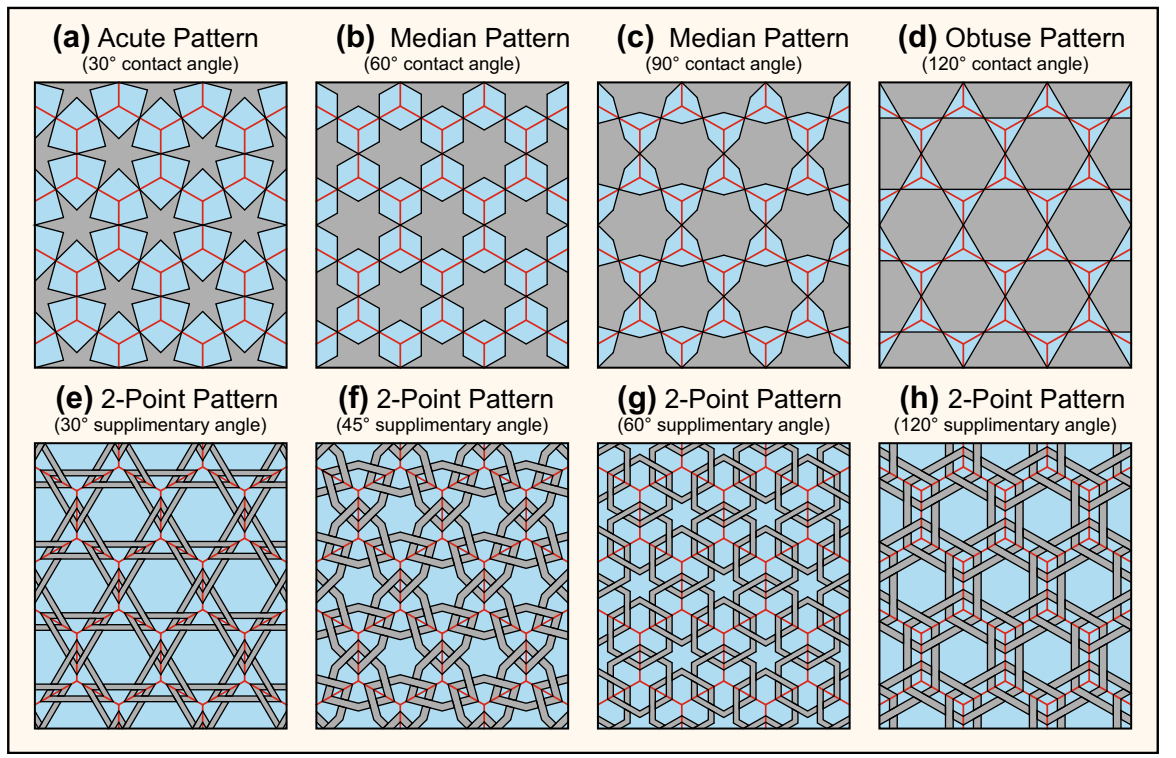

Fig. 10 Eight representative patterns easily created from the $6^{3}$ regular grid of hexagons

isometric or orthogonal grid. What is certain is that almost all of the ninth- and tenthcentury prototypical geometric patterns can be easily created using the polygonal technique. It is significant that when considered from the perspective of this design methodology, the underlying generative tessellations for almost all of these early examples are comprised of regular polygons. As the use of this regular polygonal methodology became more sophisticated, the resulting geometric patterns became more diverse and more complex; and the prevalence of such patterns became sufficiently common to warrant their own descriptive classification: the system of regular polygons.

The growth in complexity of geometric patterns made from the system of regular polygons is directly associated with the expansion of knowledge of the tessellating potential of the regular polygons. Among the most basic patterns created from this system are those created from the simple $6^{3}$ regular grid of only hexagons. Figure 10 illustrates just eight of the many historical patterns that can be created from this simple hexagonal grid. The regular polygons that comprise this system are the equilateral triangle, square, hexagon and dodecagon. ${ }^{6}$ The semi-regular grids and 2-uniform grids incorporate more than a single variety of regular polygon, and greater diversity of angles at the vertices of the grid. These conditions result in

\footnotetext{
${ }^{6}$ I exclude the octagon from the system of regular polygons for two practical reasons: the octagon only assembles with one other regular polygon, the square, to cover the two-dimensional plane in the $4.8^{2}$ semi-regular tessellation, and this limitation sets it apart from the tessellating flexibility of the other regular polygons within this system; and the octagon and square are members of the 4-fold system $A$ and the patterns that the $4.8^{2}$ tessellation produces are, thereby, more akin to those of the 4-fold system $A$. For these reasons, I exclude the octagon from the system of regular polygons and place it into the 4fold system $A$.
} 


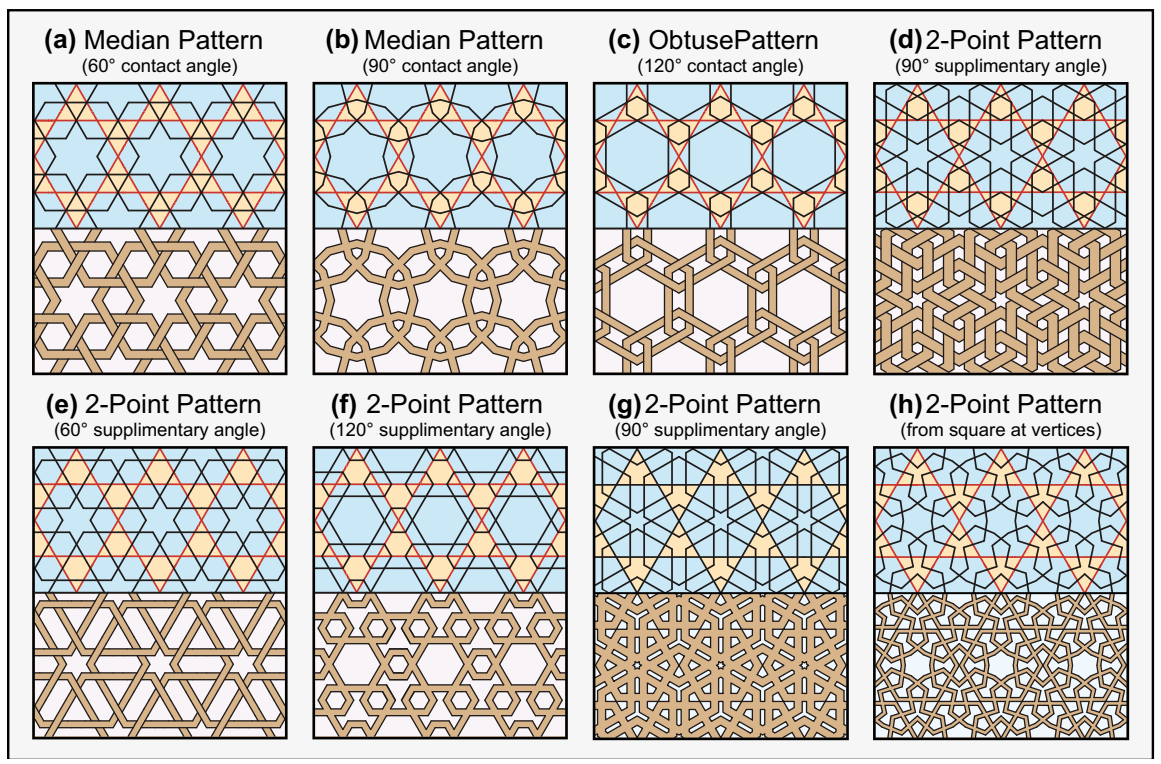

Fig. 11 Eight representative patterns created from the 3.6.3.6 semi-regular tessellation of triangles and hexagons

geometric designs of significantly greater complexity than those that utilize a single regular polygon as their formative structure. The patterns in Fig. 11 are created from the 3.6.3.6 underlying tessellation of triangles and hexagons. This semi-regular grid is responsible for considerably more historical designs than the eight represented in this illustration. Figure $11 \mathrm{a}$ is a median pattern with $60^{\circ}$ contact angles that was frequently used throughout Muslim cultures, and early examples include an Umayyad window grille from the Great Mosque at Cordoba in Spain (987-99), and a wooden top rail in the Seljuk minbar of the Friday Mosque at Abyaneh, Iran (1073). The pattern in Fig. $11 \mathrm{~b}$ is a median pattern with $90^{\circ}$ contact angles that was also well known throughout Muslim cultures. This design is made up of superimposed dodecagons, and there are several variations to this design that differ in the size of the dodecagons relative to their placement within the same isometric repetitive structure (Bonner 2016). An early Seljuk example of this particular variation is found at the Friday Mosque at Golpayegan in Iran (1105-18). A beautiful Ilkhanid example of the well-known obtuse design in Fig 11c was used in a frontispiece of the thirty-volume Quran (1313) commissioned by Sultan Uljaytu and calligraphed and illuminated by 'Abd Allah ibn Muhammad al-Hamadani. ${ }^{7}$ The 2-point design in Fig. 11d is comprised of a network of meandering lines that do not loop back onto themselves to close a geometric circuit. This dynamic design was used during the Seljuk Sultanate of Rum at the Ali Tusin tomb tower in Tokat, Turkey (1233-34), and in the window grilles of the Sultan Qala'un funerary complex in Cairo (128485). The 2-point pattern in Fig. 11e is relatively common, and a fine Mudejar

\footnotetext{
7 This Ilkhanid Quran is in the National Library in Cairo: 72, pt.19.
} 
example is found in the raised brick ornament on the north side of the Cathedral of San Salvador at the Aljafería Palace in Zaragoza, Spain. The less common 2-point design in Fig. 11f was used by Atabeg artists on the sarcophagus in the mausoleum of Sultan Duqaq in Damascus (1095-1104), and in a Ghurid mihrab at Lashkari Bazar in Afghanistan (after 1149). The two 2-point designs in Fig. 11g, $\mathrm{h}$ incorporate the 3.6.3.6 semi-regular grid itself into the completed design. This is highly unusual among the other generative system, but occasionally found among patterns created from the system of regular polygons. As per Fig. 11d, the applied pattern lines in Fig. $11 \mathrm{~g}$ are placed perpendicular to the edge, with $90^{\circ}$ supplementary angles. The difference between these two designs results from the critical placement of the two orientating points used for the two applied pattern lines for each polygonal edge. In the case of Fig. 11d, each polygonal edge is divided into quarters, and in Fig. 11g, they are divided into thirds. Fig. $11 \mathrm{~g}$ was used by an Armenian Christian artist on a stone Khatchkar (fourteenth century), as well as in the Chaghatayid ornament of the Apak Khoja mausoleum in Kashi, western China (c. seventeenth century). The pattern lines in Fig. 11h are laid out with squares placed at each vertex of the generative tessellation, and arbitrarily added 6-pointed stars within each hexagonal cell. This design was used in the Mamluk madrasa of Aqbughawiyya (1340) at the al-Azhar mosque in Cairo.

The incorporation of the dodecagon into the underlying tessellation of patterns created from the system of regular polygons produces designs with 12-pointed stars. There were a great number of such patterns used throughout the history of this ornamental tradition (Bonner 2016). Figure 12 illustrates four geometric patterns that are created from the $3.12^{2}$ semi-regular tessellation of triangles and dodecagons. This is the least complex semi-regular tessellation that employs the dodecagon, but the patterns that it creates are very beautiful. Figure 12a is a median pattern that employs $60^{\circ}$ crossing pattern lines placed at the midpoints of the underlying polygonal edges. This is a very common 3-fold pattern, and early Seljuk examples include the east tomb tower at Kharraqan (1067), and the Friday Mosque

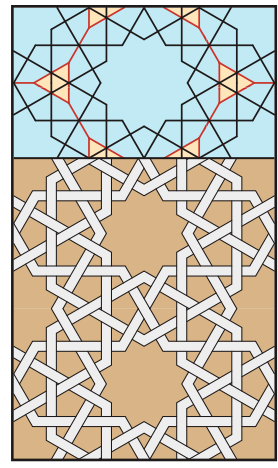

(a)

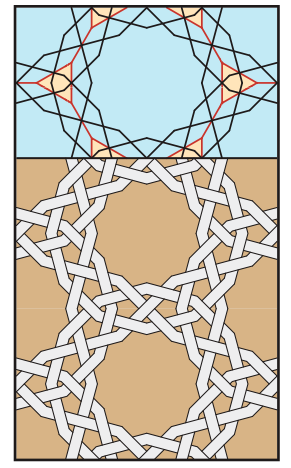

(b)

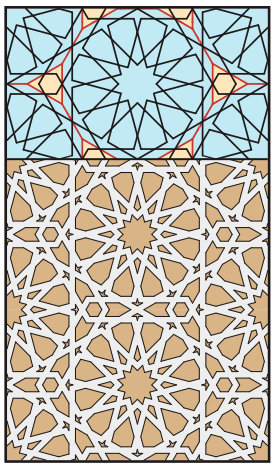

(c)

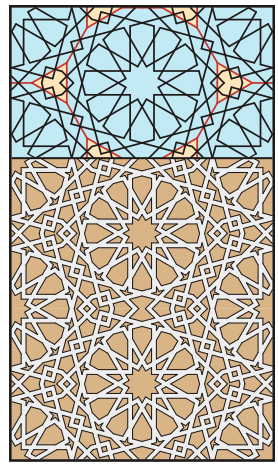

(d)

Fig. 12 Four geometric designs created from the system of regular polygons that are derived from the $3.12^{2}$ semi-regular tessellation of triangles and dodecagons 
of Golpayegan, Iran (1105-18). An early Fatimid example is found at the Sayyid Ruqayya Mashhad in Cairo (1133). Multiple examples from the Seljuk Sultanate of Rum include the Great Mosque at Kayseri, Turkey (1205), and the Great Mosque at Akşehir near Konya (1213). A contemporaneous Ayyubid example is found at the Imam al-Shafi'i mausoleum in Cairo (1211). Multiple Mamluk examples include a window grille at the Ibn Tulun mosque in Cairo (1296), a door at the Vizier al-Salih Tala'i mosque in Cairo (1303), and the Amir Salar \& Amir Sanjar al-Jawli complex in Cairo (1303-04). A contemporaneous Ilkhanid example was used at the mausoleum of Uljaytu in Sultaniya, Iran (1307-13). Figure 12b is a median pattern (by author) with $90^{\circ}$ crossing pattern lines. While not known to the historical record, this design is appealing and certainly conforms to the aesthetics of this ornamental tradition. The obtuse design in Fig. 12c includes the typical rosette treatment to the 12-pointed star inside each dodecagon. One of the earliest examples of this wellknown design is a Seljuk raised brick panel from the southern iwan of the Friday Mosque at Forumad in northeastern Iran (twelfth century). An Ilkhanid example is found at the mausoleum of Uljaytu in Sultaniya, Iran (1307-13); and locations of later Mamluk examples include the Amir Aq Sunqar funerary complex in Cairo (1346-47), and the Sultan Qansuh al-Ghuri complex in Cairo (1503-05). It is worth noting that this obtuse pattern can also be created from an altogether different nonsystematic underlying tessellation (Bonner 2016), but due to space limitations this is not shown. Figure $12 \mathrm{~d}$ is a 2-point pattern with the same variety of added rosette as in Fig. 12c. Examples of this design include an illuminated page from a Quran (1303-07) produced in Baghdad at a time when the ornamental arts were still heavily influenced by Seljuk culture. This Quran was calligraphed by Ahmad ibn alSuhrawardi and illuminated by Muhammad ibn Aybak ibn 'Abdullah. A Mamluk example of this 2-point pattern is found in a stone mosaic panel from the Amir Aq Sunqar funerary complex in Cairo (1346-47).

Patterns created from the system of regular polygons occasionally employ a nonregular ditrigonal shield module that can originate as an interstice of otherwise regular polygons within a tessellation. Figure 13 illustrates two median patterns created from underlying tessellations with ditrigonal modules. Figure $13 \mathrm{a}$ is an isometric design with crossing pattern lines that have $60^{\circ}$ contact angles. This was used by artists working in multiple Muslim cultures, including: the Seljuk Sultanate of Rum at the Yelmaniya mosque in Cemiskezck, Turkey (1274); the Mamluks at the Aqburghawiyya madrasa (1340) in the al-Azhar mosque in Cairo; and the Ottomans in their restoration of the Dome of the Rock in Jerusalem. Figure 13b is an orthogonal design with four clustered ditrigonal modules that, along with four triangles, fill regions that would otherwise be dodecagons. The crossing pattern lines of this design include $45^{\circ}, 60^{\circ}$ and $90^{\circ}$ contact angles. This exceptional pattern was first used by Ghurid artists at both the minaret of Jam in Afghanistan (1174-75 or 1194-95), and at the Shah-i Mashhad in Gargistan, Afghanistan (1176), and later during the Seljuk Sultanate of Rum at the Alaeddin mosque in Konya (1219-21). As seen in these two examples, the pattern lines within the ditrigonal modules create distinctive motifs that would not otherwise be produced from the system of regular polygons. 


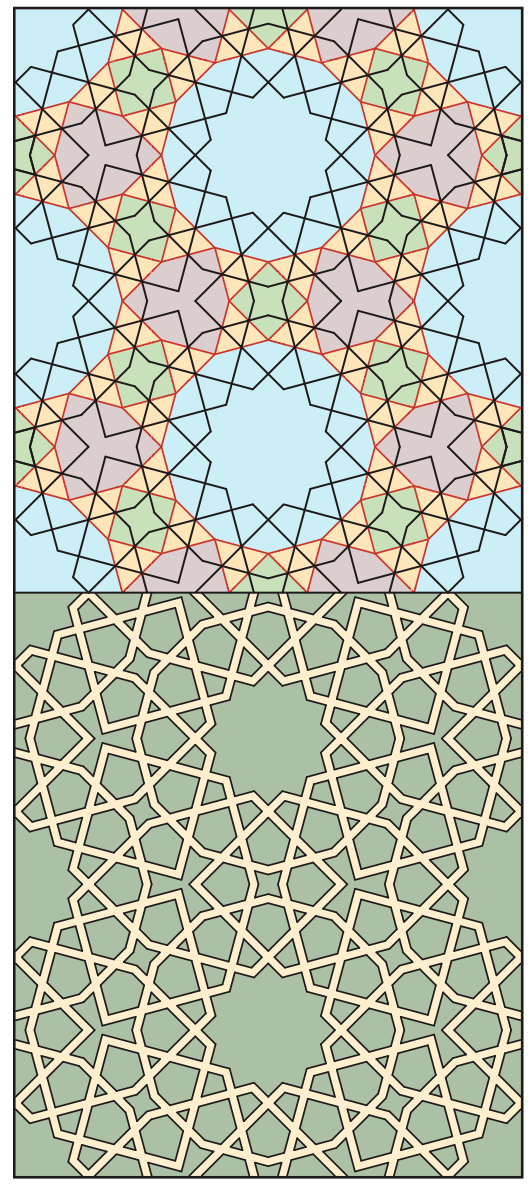

(a)

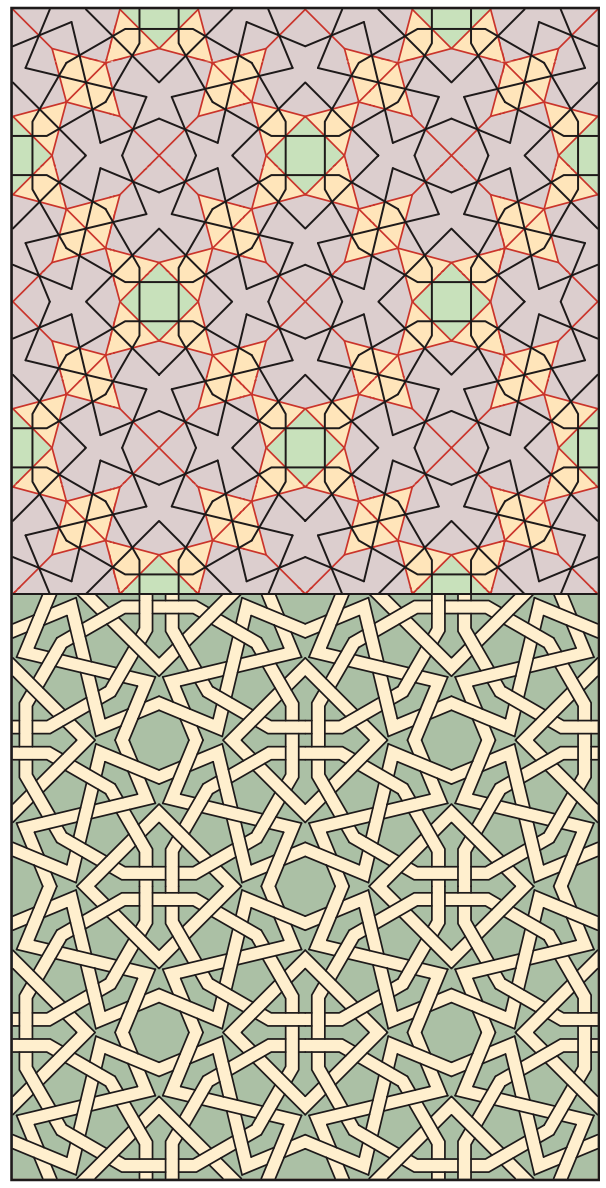

(b)

Fig. 13 Two designs created from the system of regular polygons that employ a ditrigonal module within their underlying generative tessellations

\section{The Two 4-Fold Systems}

The two 4-fold systems each employ the octagon as the primary polygonal module. Most of the patterns that these two systems create repeat upon the orthogonal grid, although patterns with $45^{\circ}$ and $135^{\circ}$ angled rhombic repeat units were occasionally employed, as were patterns with rectangular repeat units. Patterns with radial symmetry are also possible with these systems, although infrequently used. Figure 14 illustrates the polygonal modules of the 4-fold system A, along with their associated pattern lines in each of the four pattern families. The large and small octagons, as well as the square, are the only modules that are regular polygons. The 4-fold system $A$ is comprised of a relatively large number of polygonal modules, resulting in a virtually unlimited number of potential underlying generative 


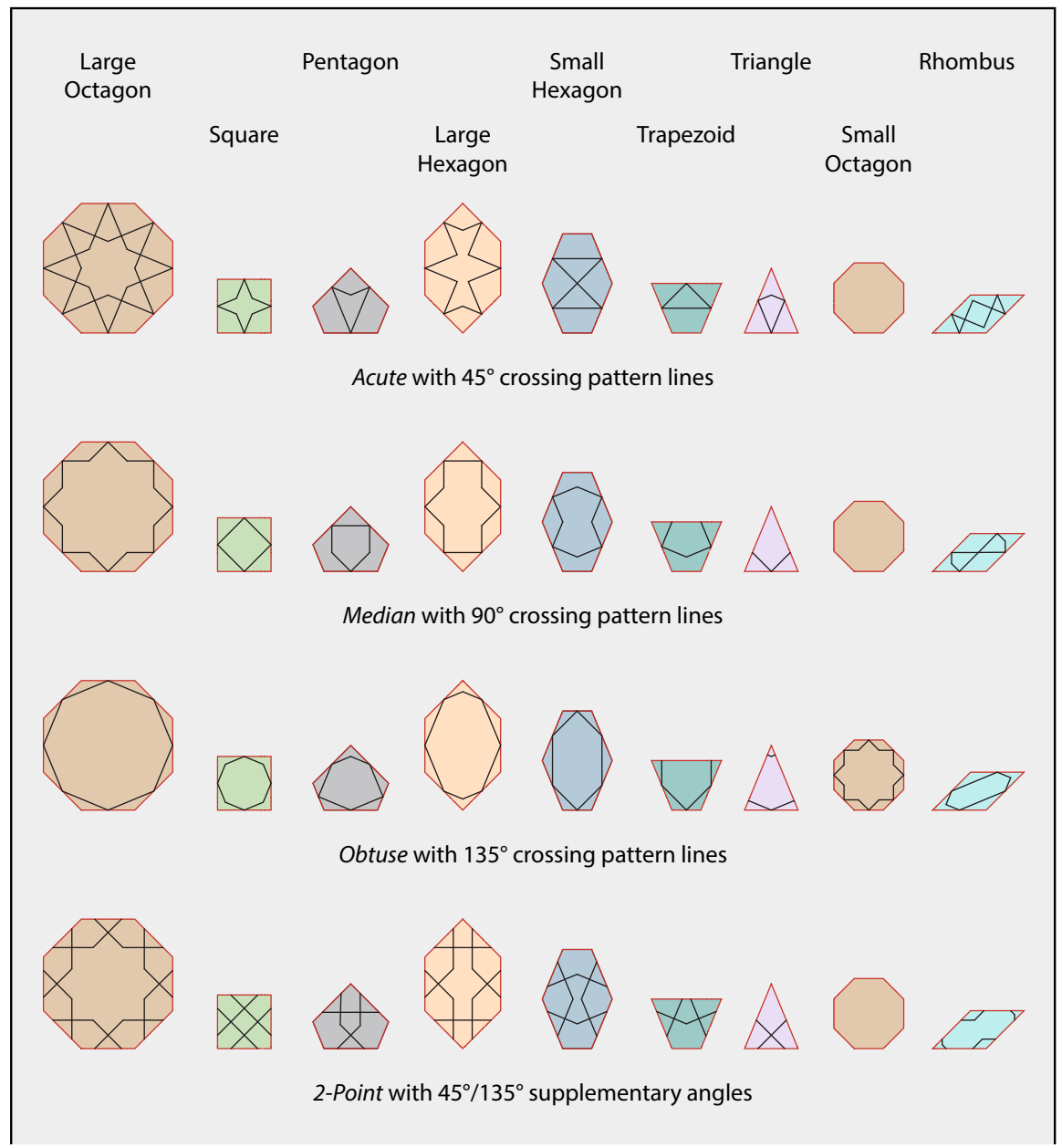

Fig. 14 The polygonal modules of the 4-fold system $A$ with their associated pattern lines in each of the four standard pattern families

tessellations. Ghaznavid and Qarakhanid artists are responsible for the earliest patterns created from the 4-fold system A. These date to the first quarter of the eleventh century. Seljuk and Ghurid artists adopted this methodological system within half a century, and the diversity of patterns created by these Eastern cultures is remarkable. The rapid westward spread of Seljuk influence introduced this system to the Artuqids, Zangids, and the Seljuk Sultanate of Rum; by which time it had become part of the standard geometric design repertoire of these regions. The acute, median, obtuse and 2-point designs in Fig. 8, as well as the three variations in Fig. 9, are produced from an underlying tessellation that employs just the large hexagon and square modules from the 4-fold system A. The absence of an octagon within this underlying tessellation means that there are no primary stars within the 


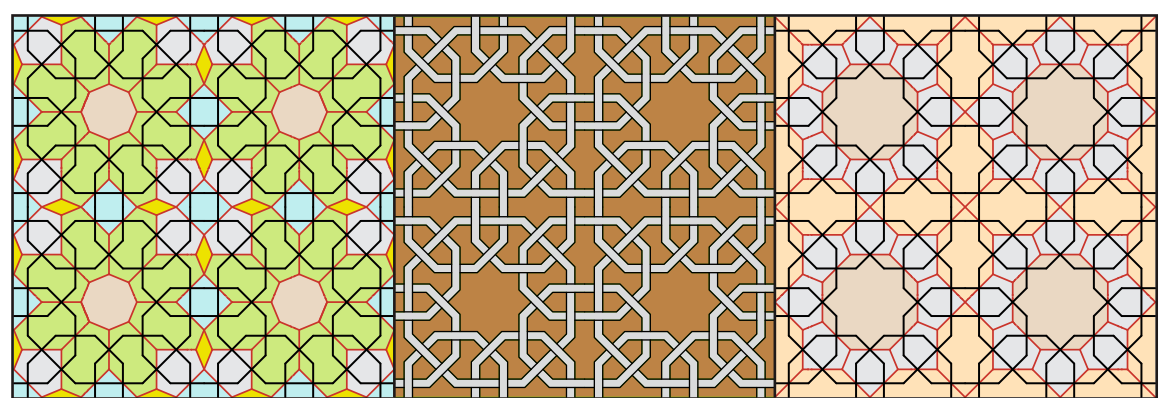

Fig. 15 Two alternate derivations of a median design created from the modules of the 4-fold system A

pattern matrix. Designs of this variety are referred to as field patterns. The median design in Fig. 15 illustrates how a single pattern can sometimes be created from two separate underlying tessellations, each of which is comprised of a different combination of polygonal modules from the same system. The earliest occurrences of this design are from the raised brick ornament of the Seljuks and Ghurids in Khurasan, including: the minaret of the Friday Mosque at Damghan, Iran (1080); an example that is incorporated into a Kufi inscription at the Friday Mosque at Golpayegan, Iran (1105-18); the minaret of Daulatabad in Afghanistan (1108-09) (Fig. 5); the minaret of the Friday Mosque at Saveh, Iran (1110); the Friday Mosque at Sangan-e Pa'in, Iran (late twelfth century); and the minaret of Jam in central Afghanistan (1174-75 or 1194-95). This very popular design is also included in the anonymous treatise On Similar and Complementary Interlocking Figures [Anonymous: fol. 196r]. Later examples of this design include: the Shaybanid polychromatic brick ornament at the Shir Dar madrasa in Registan Square, Samarkand (1619-36); the Mughal stone mosaics of the mausoleum of Akbar in Sikandra, India (1613); and the Ottoman ornament of the Bayt Ghazalah private residence in Aleppo (seventeenth century).

The 4-fold system $B$ has fewer polygonal elements, allowing for less tessellating diversity than that of the 4-fold system $A$. As with the 4-fold system A, this system is responsible for a wide variety and large quantity of distinctive and beautiful designs from the historical record. The architectural record indicates that the development of the 4-fold system B took place during the first half of the twelfth century under Qarakhanid, Seljuk and Ghurid patronage. Figure 16 illustrates the modules that make up the 4-fold system B, along with their associated pattern lines in each of the four pattern families. There are considerably fewer patterns produced from this system in the eastern regions during this early period than those of the 4-fold system $A$. The predominance of early patterns created from the 4-fold system $B$ are found in the western regions of Seljuk influence, and were produced under the patronage of the Ildegizids, Zangids, Ayyubids, and the Seljuk Sultanate of Rum. By far the most commonly used underlying tessellation of the 4-fold system $B$ is comprised of just octagons and pentagons. Figure 17 illustrates the patterns from each of the four pattern families that are created from this underlying tessellation. The acute pattern in Fig. 17a is the most ubiquitous design produced from this system, and examples 


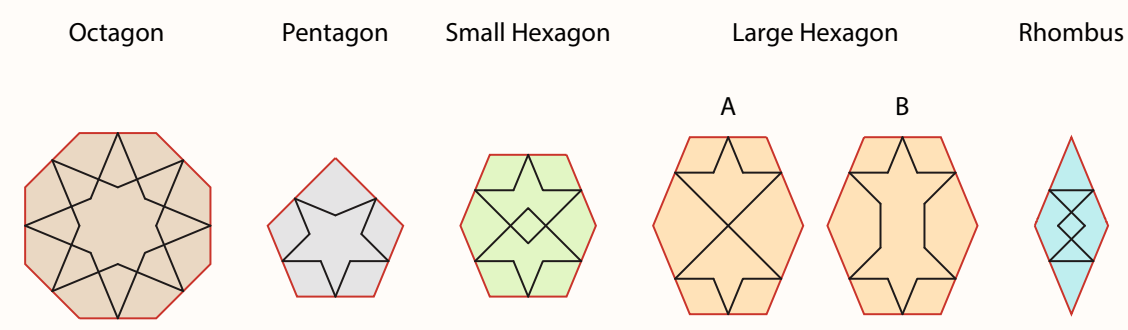

Acute with $45^{\circ}$ crossing pattern lines
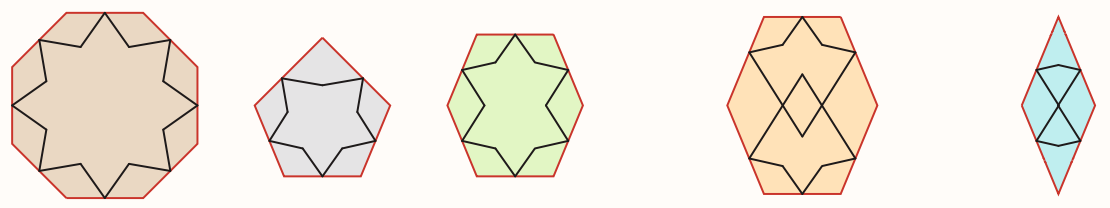

Median with $70.5288 . .{ }^{\circ}$ crossing pattern lines
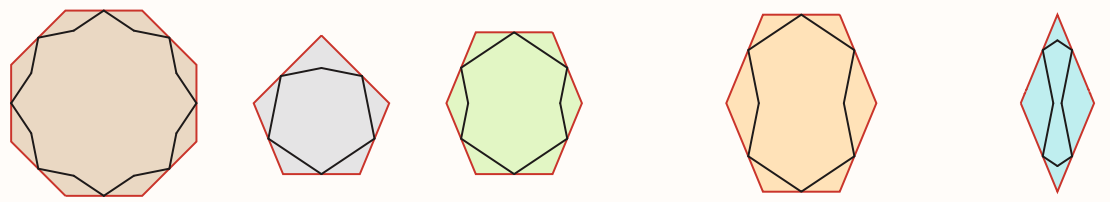

Obtuse with $112.5^{\circ}$ crossing pattern lines
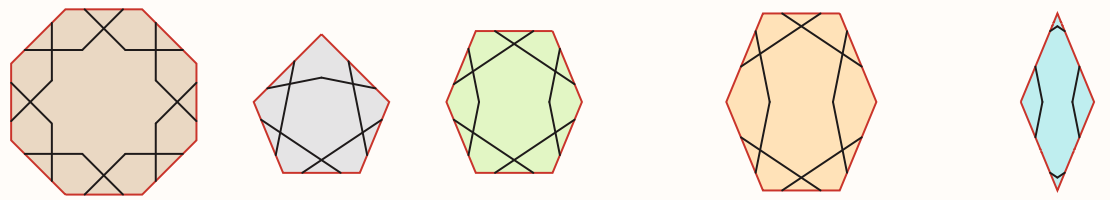

2-Point with $45^{\circ} / 135^{\circ}$ (Octagon) and $33.75^{\circ} / 146.25^{\circ}$ supplementary angles

Fig. 16 The polygonal modules of the 4-fold system $B$ with their associated pattern lines in each of the four standard pattern families

are found throughout the Islamic world. The earliest extant example appears to be from the arch spandrel of the Seljuk mihrab in the Friday Mosque at Sin, Iran (1134). Other early locations are predominantly in Iraq and the Levant, and include: the base of the Zangid minaret of the Great Mosque of Nur al-Din in Mosul, Iraq (1170-72); two side panels in the Ayyubid stone mihrab in the Zahiriyya madrasa in Aleppo, Syria (1217); a wooden soffit at the Farafra khanqah (Dayfa Khatun) in Aleppo (1237-38); and the back wall of the arched recess in the Ayyubid wooden 


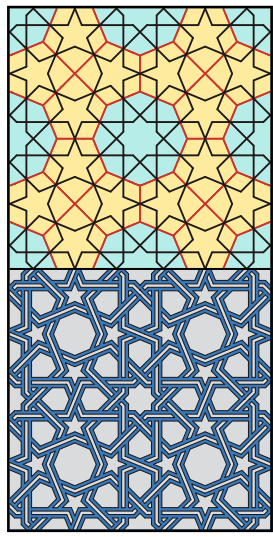

(a)

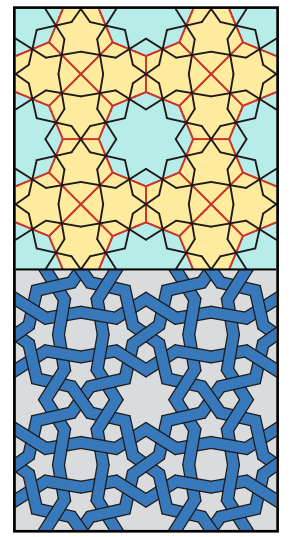

(b)

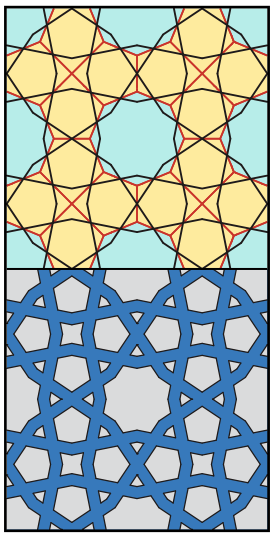

(c)

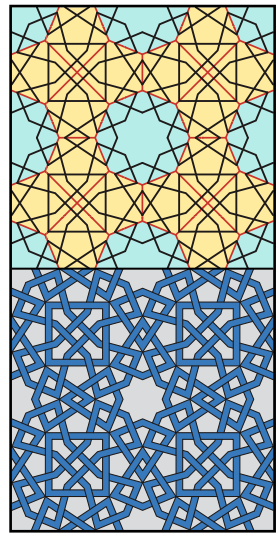

(d)

Fig. 17 Patterns from each of the four patterns families produced from the same underlying tessellation of modules from the 4-fold system $B$

mihrab (1245-46) of the Halawiyya mosque in Aleppo. Anatolian examples from the Sultanate of Rum include: the Donar Kunbet tomb tower in Kayseri (1276); the Gök madrasa in Sivas (1270-71); the Arslanhane mosque in Ankara (1289-90); and the Esrefoglu Süleyman Bey mosque in Beysehir (1297). An early Mamluk example was used in the window grilles of the Sultan Qala'un funerary complex in Cairo (1284-85). There are also many fine examples from the eastern regions produced after the Mongol destruction. These include a cut-tile mosaic panel from the Abdulla Ansari complex in Gazargah near Herat, Afghanistan (1425-27), and a marble jali screen from the tomb of Salim Chishti at Fatehpur Sikri (1605-07). This has the distinction of including the underlying generative tessellation as part of the completed screen, thereby providing valuable evidence of the historicity of the polygonal technique. Somewhat surprisingly, the median pattern in Fig. 17b (by author) does not appear to have been used historically. The obtuse pattern in Fig. 17c enjoyed limited historical use, with an Ayyubid example used in an inlaid stone panel at the Firdaws madrasa in Aleppo (1235-36). The 2-point pattern in Fig. 17d was used by Ghurid artists at the Friday Mosque at Herat, Afghanistan (1200); and close variations of this design include a Seljuk Sultanate of Rum example from the Bimarhane hospital in Amasya, Turkey (1308-09); and three Mamluk examples from the Aqbughawiyya madrasa (1340) in the al-Azhar mosque in Cairo, the Sultan al-Mu'ayyad Shaykh complex in Cairo (1415-22), and in the stone ceiling of the Ashrafiyya madrasa in Jerusalem (1482).

\section{The 5-Fold System}

Almost all of the innumerable patterns with 5-fold symmetry and 10-pointed stars that are found throughout the Islamic world have their origin in the 5-fold system. The repeat units of patterns generated from this system are predominantly either 


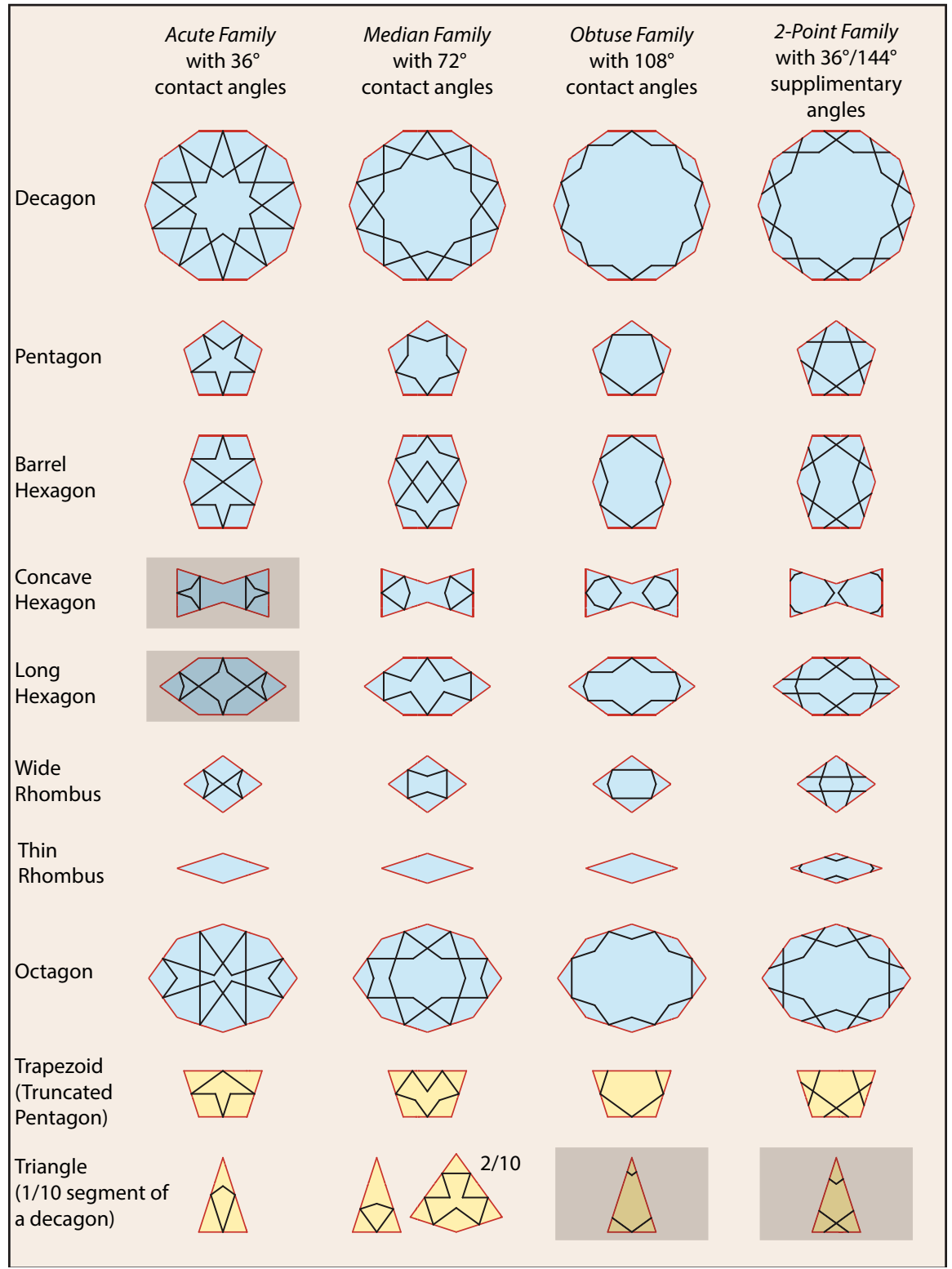

Fig. 18 The polygonal modules of the 5-fold system with their associated pattern lines in each of the four standard pattern families

rhombic or rectangular. Less common are patterns with hexagonal repeat units, and less common still are those with radial symmetry (Bonner 2016). The 5-fold system has a larger number of polygonal modules than either of the 4-fold systems. Some of these were more widely used than others. Figure 18 illustrates the primary modules 
that comprise this system. Just two of these are regular: the decagon and pentagon. As with all of the polygonal systems, the applied pattern lines in each pattern family are directly determined by the geometry of the primary regular polygon-in this case, the decagon. ${ }^{8}$ The visual character of the applied pattern lines of certain modules (shaded) within specific pattern families is less acceptable to the aesthetics of this tradition. For example, the pattern lines created from the concave and long hexagons do not make acceptable design features within the acute family. Similarly, the triangles within the obtuse and 2-point families are problematic. Yet these same modules make highly acceptable design features within the other pattern families. There are two edge lengths among the polygonal modules within this system: the shorter being the length of the edges of the regular decagon and pentagon, and the longer being equal to the distance from the center of the decagon to one of its vertices. The ratio of these two edge lengths is the golden section $(1: 1.618033987 \ldots)$; and indeed, the proportional relationships inherent within 5-fold geometric patterns are imbued with this geometric ratio (Bonner 2003: Fig. 14). The upper eight polygonal modules in this illustration have only the shorter edge length, while the lower two modules have both edge lengths. ${ }^{9}$ The two edge lengths within this system provide for a greater diversity of underlying tessellations and greater range of design features among the resulting patterns in each of the pattern families.

Figure 19 illustrates all four of the pattern families as applied to the most basic underlying generative tessellation produced from the 5-fold system, and each of the four patterns created from this tessellation was widely used historically. Early acute examples that employ this same underlying tessellation include the Ghurid soffit of the Taq-i Bust arch in Bust, Afghanistan (1149) (Fig. 4), and a border within the Seljuk iwan at the Friday Mosque at Gonabad, Iran (1212). Among the earliest examples of the median pattern produced from this underlying tessellation is a Timurid cut tile mosaic panel from the Bibi Khanum mosque in Samarkand (13991405). The northeast dome chamber of the Friday Mosque at Isfahan employs the first example of the obtuse pattern created from this underlying tessellation (Fig. 30), and a slightly later example is found at the Friday Mosque at Golpayegan, Iran (1105-1118). The earliest example of the 2-point pattern produced from the same underlying tessellation is from the magnificent Seljuk entry tympanum at the Gunbad-i 'Alaviyan in Hamadan, Iran (late twelfth century). It should be noted that the 2-point pattern at the Gunbad-i 'Alaviyan includes an arbitrarily added geometric rosette inside each of the 10-pointed stars (see footnote 8) that is not included in this illustration. This additive treatment was common with 2-point and obtuse patterns created from the 5-fold system, and is analogous to the pattern line treatments within the dodecagons in Fig. 12c, d.

\footnotetext{
8 The median, obtuse and 2-point pattern lines applied to the decagons in Fig. 18 represent their most basic form. However, each of these received significant additive variation within this ornamental tradition, often determined by stylistic preferences within specific Muslim cultures (Bonner 2016). In the interests of space, these are not shown in this illustration.

9 There are several historical examples of additional modules that employ only the longer edge length (Bonner 2016), but in the interests of space, these are not shown in this illustration.
} 


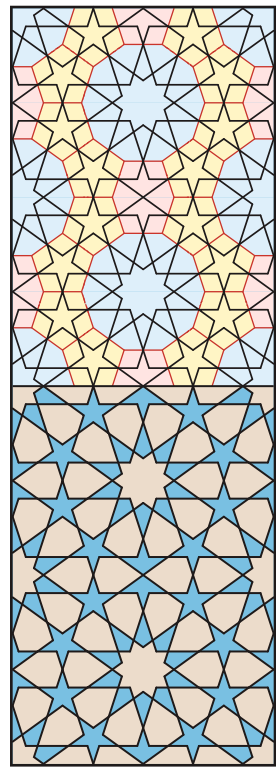

acute

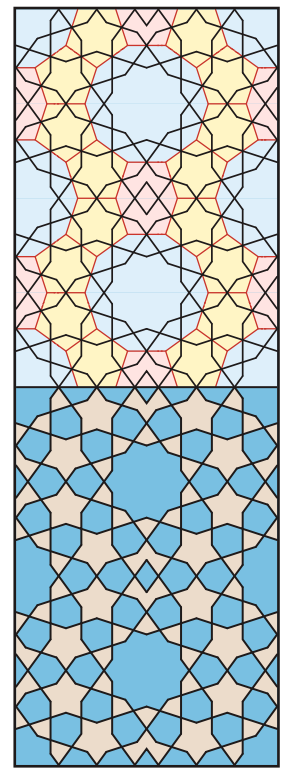

median

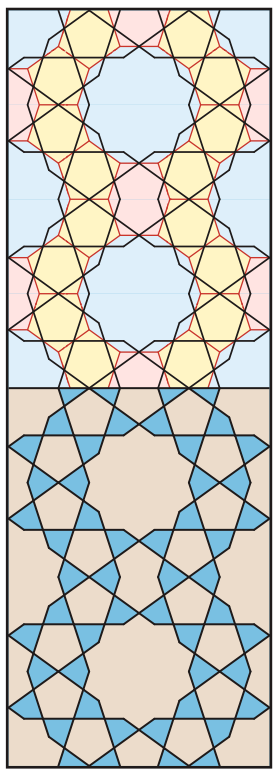

obtuse

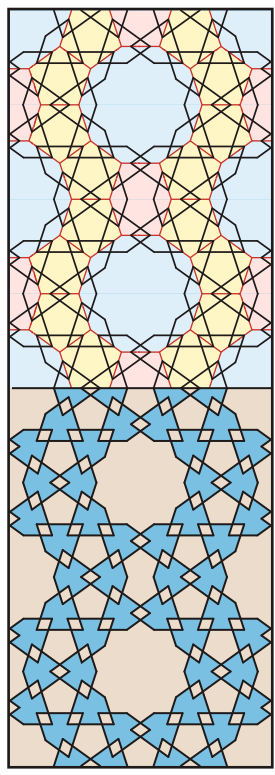

2-point

Fig. 19 The most common 5-fold designs in each of the four pattern families created from the same underlying tessellation from the 5-fold system

The versatility and visual appeal of patterns made from the 5-fold system led to its rapid spread throughout Muslim cultures, and outstanding examples are to be found in diverse ornamental media throughout the length and breadth of this ornamental tradition. The three examples of 5-fold geometric designs in the northeast dome chamber of the Friday Mosque at Isfahan are the earliest known to the historical record. Within a decade of their construction, the Ghaznavids also employed patterns with 5-fold symmetry in the ornament for the minaret of Mas'ud III in Ghazni, Afghanistan (1099-1115), although these are not produced from the 5-fold system (Bonner 2016). By the middle of the twelfth century Ghurid artists also made use of patterns created from the 5-fold system, followed by the Qarakhanids some 30 years later. And as with the 4-fold systems $A$ and $B$, the 5-fold system spread westward from Khurasan and Persia into regions under Seljuk influence, and subsequently became an ubiquitous feature of the ornamental arts of Muslim cultures generally.

\section{The 7-Fold system}

Among the most fascinating systematic geometric patterns to have been created by Muslim artists are a relatively small number of designs with 7-fold symmetry. However, the small number of surviving historical examples of such patterns begs the question as to the extent to which the artists were aware of the systematic 
repetitive potential of the underlying polygonal components that made up the generative tessellations. This variety of pattern is very beautiful, and were the systematic potential for these components known by the artists working with geometric patterns generally, one would assume that, as with 5-fold patterns, there would be far more examples found throughout the Islamic world. This paucity of examples appears to indicate the rarity of knowledge of this system among geometric artists. However tenuous our understanding of past 7-fold methodological knowledge is, it is nonetheless a fact that the relatively few 7-fold patterns in the historical record were easily created from a limited set of repetitive polygonal modules that include associated pattern lines in each of the four standard pattern families. Figure 20 illustrates a representative example of the large number of polygonal modules within the 7-fold system. As with the 5-fold system, there are just two regular polygons: the heptagon and tetradecagon (14-sided). This illustration demonstrates how the many modules in this system can be produced through four different geometric functions: interstice regions created from combinations of previously identified modules; the truncation of the two regular polygons; the intersection of the two regular polygons; and the union of the two regular polygons. It also indicates the multiplicity of edge lengths found within this system. Creating underlying tessellations from such a large selection of modules, and with multiple edge lengths is less troublesome than might first appear likely. The applied pattern lines in each of the four pattern families is not shown in this paper due to space limitations, but this is detailed elsewhere (Bonner and Pelletier 2012; Bonner 2016).

The earliest known 7-fold geometric pattern is from the northeast domed chamber of the Friday Mosque at Isfahan, and as with the earliest 5-fold patterns, the Ghaznavids included two 7-fold designs for the minaret of Mas'ud III in Ghazni, Afghanistan some 10 years later (Bonner and Pelletier 2012;

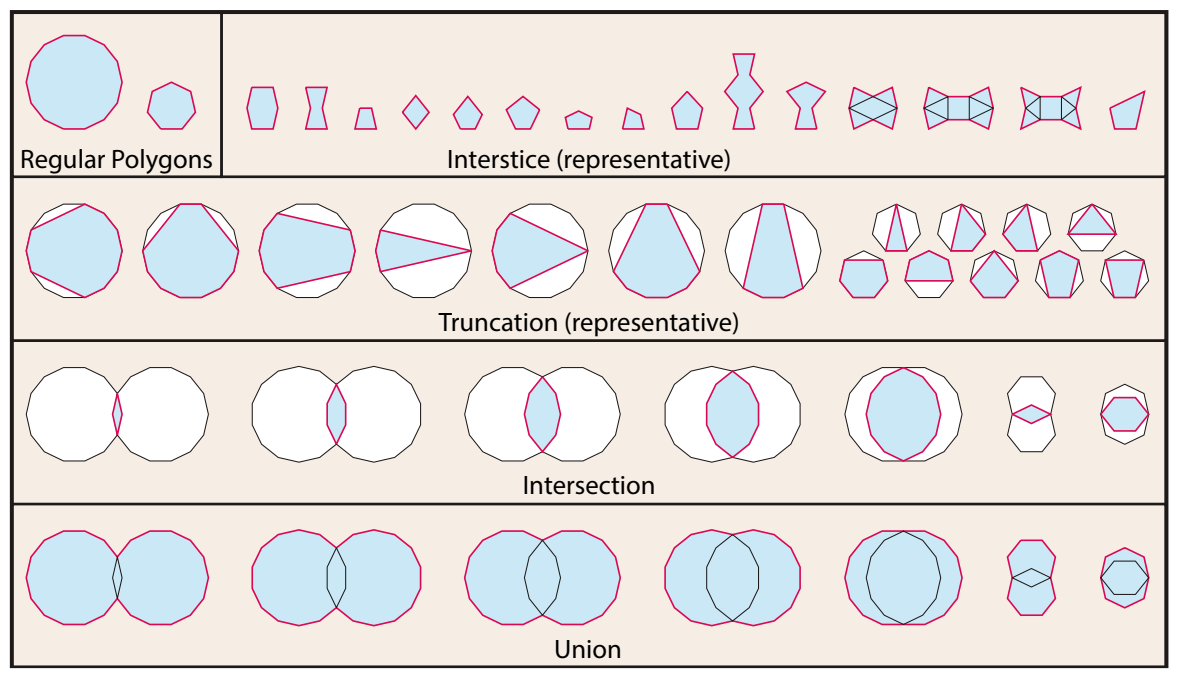

Fig. 20 Representative examples of the polygonal modules from the 7-fold system of pattern generation 
Bonner 2016). As with the 5-fold designs at this monument, the 7-fold examples are non-systematic. Each of these early Seljuk and Ghaznavid 7-fold patterns repeat upon an irregular hexagonal grid. Approximately a 100 years later, Seljuk artists in Anatolia produced three 7-fold geometric patterns that repeat upon the same irregular hexagonal grid as in Ghazni, and that use an identical underlying tessellation comprised of just heptagons and interstice pentagons (Bonner and Pelletier 2012; Bonner 2016). Figure 21 demonstrates how these three Anatolian Seljuk patterns are remarkable examples of the application of three distinct pattern families to the same underlying tessellation within the same region over the same approximate period of time. Figure 21a is an acute pattern from the Great Mosque of Dunaysir in Kiziltepe, Turkey (1200-04). Figure 21b is a median pattern (by author) that, on its own, is not known within the historical record, but was the basis for the more complex design from the minaret of Mas'ud III in Ghazni. Figure 21c is an obtuse pattern from the Egridir Han in Turkey (1229-36); and Fig. 21d is a 2-point pattern from the Great Mosque of Malatya in Turkey (1237-38). These three Anatolian examples were produced within a 38-year period, and are located within the same approximate geographical region. Almost certainly, all three are the work of a single person or artistic lineage.

In time, this 7-fold system developed in its increased use of a larger number of polygonal components with a resulting increase in complexity (Bonner and Pelletier

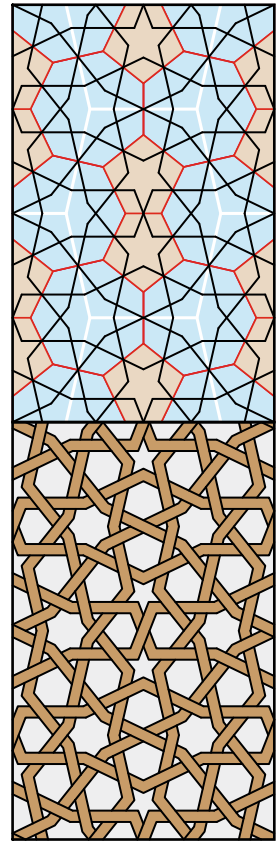

(a)

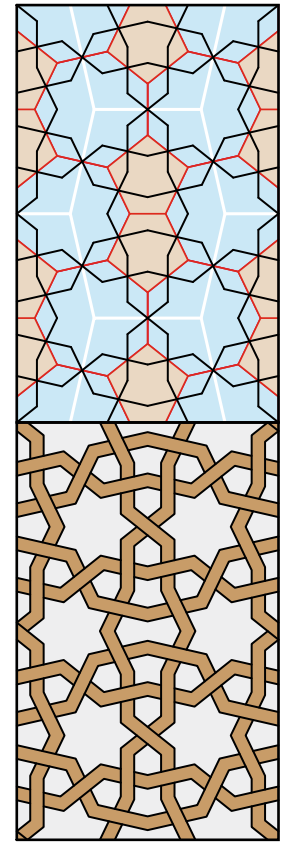

(b)

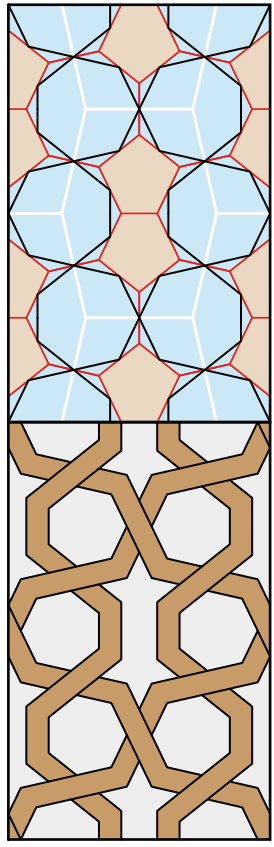

(c)

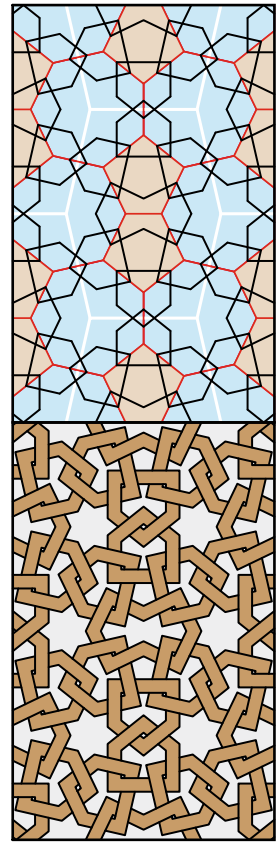

(d)

Fig. 21 Patterns from each of the four pattern families created from the same underlying tessellation of modules from the 7-fold system 
2012; Bonner 2016). A noteworthy feature that distinguishes these later examples from the earlier designs is the use of underlying tetradecagons (14-sided regular polygons) that produce 14-pointed stars. These more complex 7-fold geometric patterns originated among the Mamluks in Egypt and the Levant during the fourteenth and fifteenth centuries, and to a lesser extent, spread to a select number of artists working under Ottoman and Timurid patronage.

\section{Non-systematic Design Methodology}

In addition to geometric star patterns being produced via a systematic design methodology, Muslim artists expanded the polygonal technique to include nonsystematic designs. These are generated from underlying tessellations that include polygons that are irregular and specific to the tessellation. In contrast to the various generative systems, many of the polygonal components of such tessellations will not reassemble into other tessellations, and patterns made from this variety of underlying tessellation are therefore non-systematic. One of the virtues in the use of systems is the ease of creating new patterns through the new assemblages of the polygonal modules. To make an original design, one has only to work out a new tessellation from a predetermined set of compatible decorated polygonal elements. The creation of non-systematic underlying polygonal tessellations is entirely different. Muslim artists developed a precise design methodology that produced a wide range of underlying tessellations with polygonal components that are specific to the construction. As with the systematic approach, each non-systematic tessellation will produce geometric designs in each of the four pattern families. The similitude between non-systematic patterns and those created from the 5-fold system suggests the possibility that the mature expression of non-systematic patterns was directly influenced by the aesthetics and working practices typical of the 5-fold system (Bonner 2016). Fundamental to the creation of non-systematic underlying tessellations is the use of radii matrices as an initial foundation for the construction sequence. Evidence that radii matrices were fundamental to the non-systematic use of the polygonal technique is found in many of the geometric star patterns illustrated in the Topkapi Scroll (Necipoğlu 1995). This is a unique and immensely important document in many respects, including the insight it provides into the methodology employed for constructing complex geometric star patterns. The maker of the Topkapi Scroll used a steel graver to scribe non-inked "dead drawing" reference lines into the paper, and included among these barely visible scribed lines are radii matrices. These articulate the regions of primary and secondary local symmetry, and relate directly to the construction of the underlying polygonal tessellations, most frequently illustrated in finely dotted lines of red ink, upon which the typically black pattern lines are positioned. From the many examples in the Topkapi Scroll, it is possible to extrapolate the method for creating underlying generative grids from radii matrices. Figure 22 provides a step-by-step sequence for creating an underlying tessellation from a radii matrix. Step 1 places 24 radii at each vertex of the square repeat unit. Step 2 draws a circle that is tangent to the solid (nondashed) radii. This circle is used to determine the edges of the dodecagons, as well 


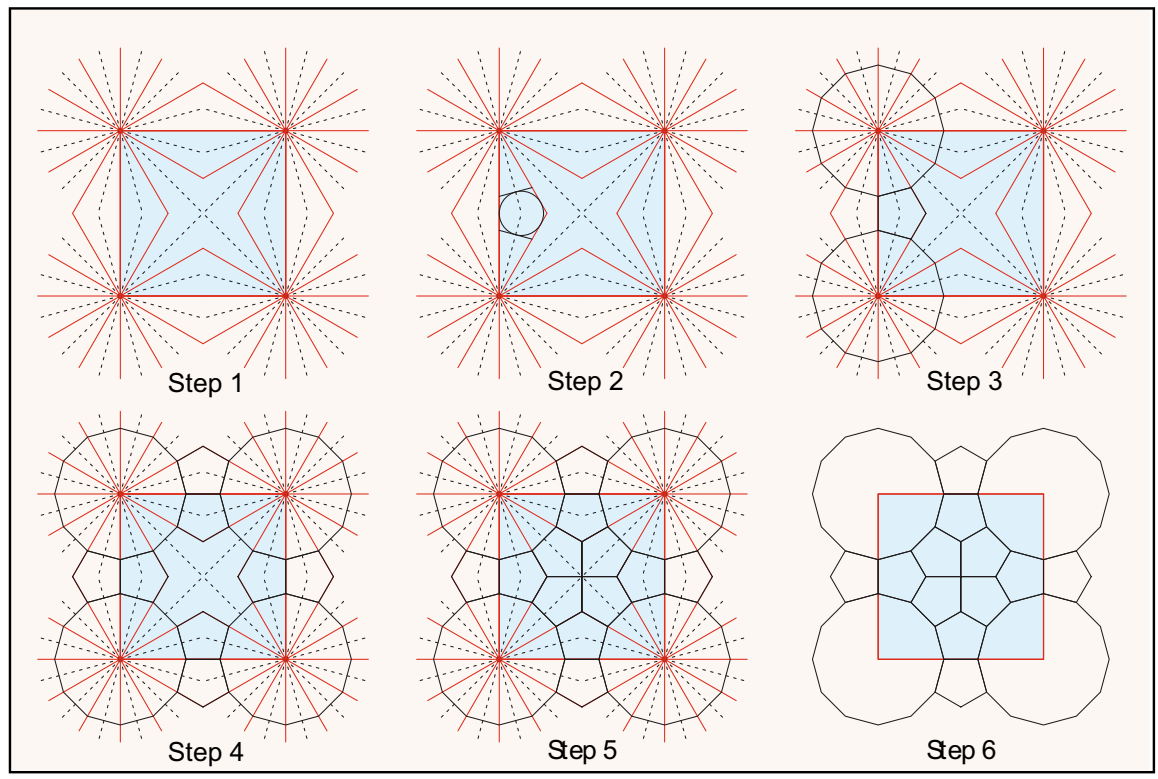

Fig. 22 A construction sequence for a non-systematic 4-fold underlying tessellation created from a radii matrix

as the separating pentagon. Step 3 completes the dodecagons and separating pentagon. Step 4 rotates these four times throughout the square repeat unit. Step 5 determines the four clustered pentagons at the center of the repeat, and Step 6 shows the completed tessellation. This tessellation is non-systematic in that the two varieties of pentagon are specific to this underlying tessellation and will not rearrange into alternative tessellations. This particular underlying tessellation was used to create numerous patterns in each of the four pattern families. Figure 23a represents the earliest extant example: an orthogonal acute design from an arched tympanum in one of the Seljuk gates of the Friday Mosque at Isfahan (after 1121-22). The artist who created this design modified the pattern in the central region of the square repeat so that the clustered pentagons make a 4-fold cruciform devise rather than four 5-pointed stars. The acute design in Fig. $23 \mathrm{~b}$ is essentially the same except that the pattern lines associated with the four clustered pentagons produce the more standard set of 5-pointed stars. This is a very well-known design that was used by many Muslim cultures in many locations. A particularly early example was used during the Seljuk Sultanate of Rum at the Great Mosque of Siirt in Turkey (1129).

The tradition of non-systematic geometric star patterns is immensely diverse and covers a wide range of symmetries and variety of repeat units. Most commonly, non-systematic geometric patterns will repeat on either the isometric or orthogonal grids, with star forms placed at the vertices of these grids. The number of points for these stars is governed by the number of angles at each vertex as a multiplier, with $n$-points being the product. In this way, patterns that repeat upon the isometric grid 


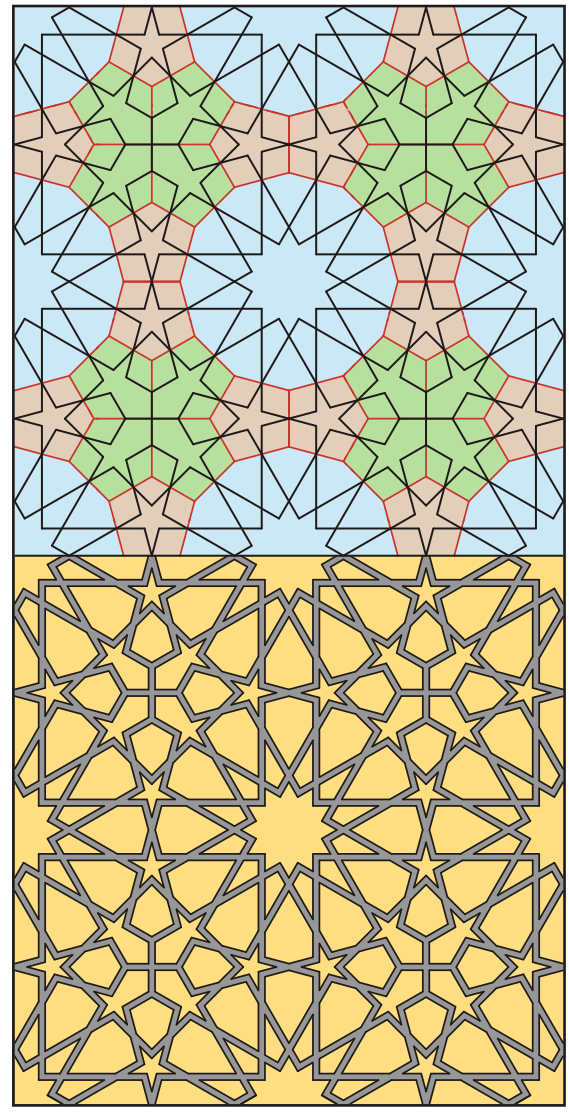

(a)

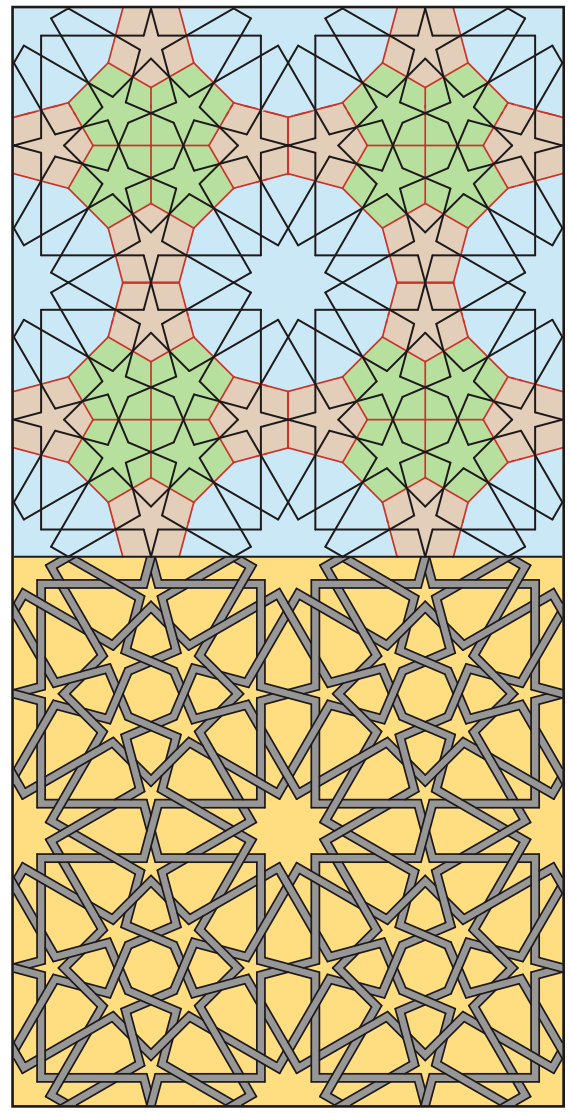

(b)

Fig. 23 Two orthogonal non-systematic acute patterns created from the same underlying tessellation illustrated in Fig. 22

will typically have 6-, 12-, 18-, 24- (etc.) pointed stars at each vertex, while the vertices of patterns that repeat on the orthogonal grid will typically have 8-, 16-, 24(etc.) pointed stars. The hexagonal grid was also employed within this tradition, and such patterns will commonly have 6-, 9-, 12-, 15-, 18- (etc.) pointed stars at the vertices of this repetitive grid. The isometric and orthogonal grids also provide for patterns that have additional varieties of local symmetry beyond those located at the vertices of the repeat unit. These are referred to as compound patterns, and the least complex will place additional stars at the vertices of the dual of the isometric or orthogonal grid - which is to say, at the centers of each repeat unit. The dual of the isometric grid is the hexagonal grid, and examples of compound local symmetry for such patterns can include star combinations of $6 \& 9$ points, $12 \& 9$ points, $12 \& 15$ points, etc. The dual of the orthogonal grid is of course another orthogonal grid, and compound patterns of this variety will typically include star combinations of $8 \& 12$, $8 \& 16,12 \& 16$, etc. Further complexity was achieved through additional centers of 

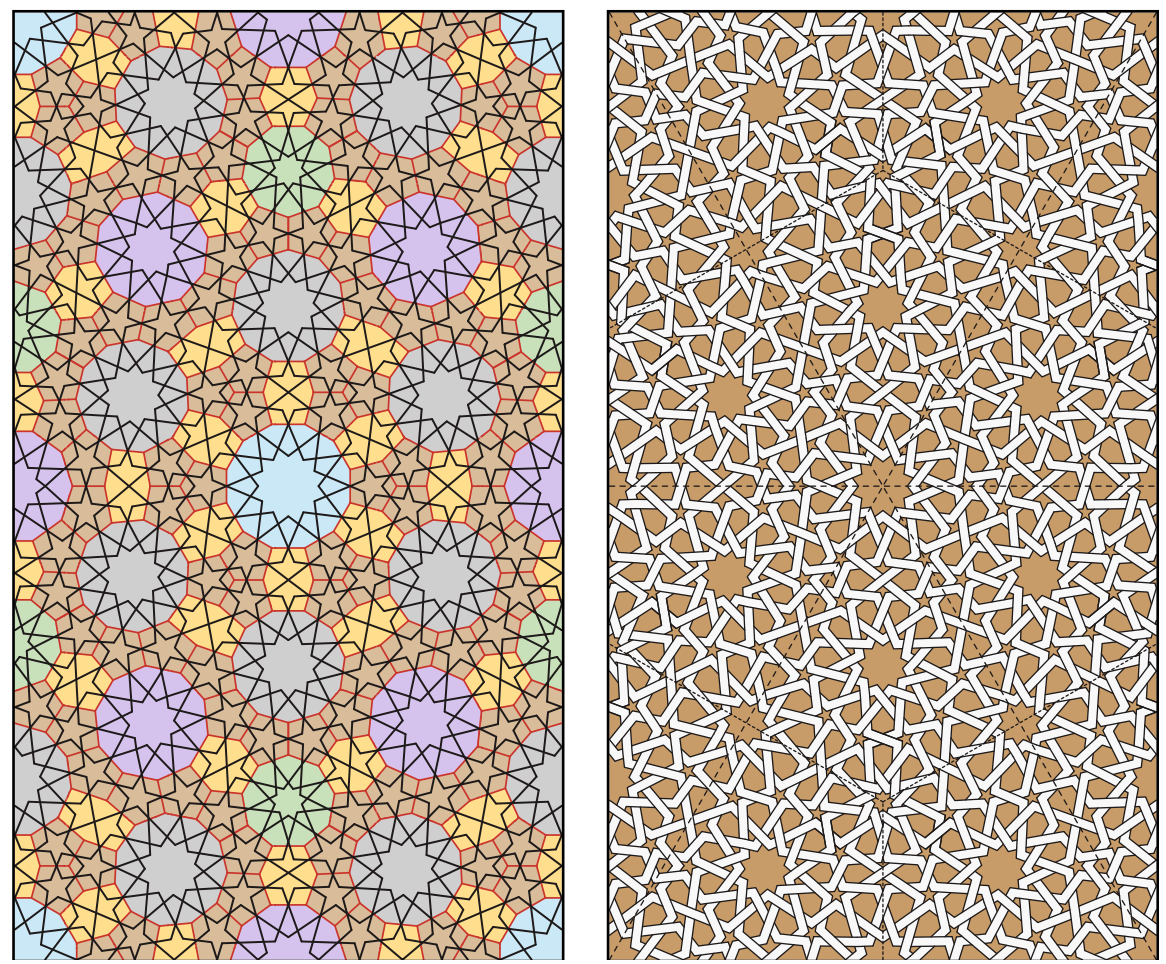

Fig. 24 A non-systematic acute design that repeats upon the isometric grid, with 9-, 10-, 11- and 12-pointed stars, along with its underlying generative tessellation

local symmetry being incorporated into the isometric or orthogonal repeat units. The locations for these additional regions of local symmetry are typically at the center points of each edge of the repeat unit, or within the field of the repeat unit. These additional locations provide the designer with greater latitude in determining the variety of local symmetry and resulting star forms. When these additional star forms are located at the midpoint of the edge of the repeat unit, they tend to have an even number of points, while the use of additional local symmetries within the field of the repeat unit is case-specific and less rigid. The isometric design in Fig. 24 incorporates all four potential regions of local symmetry within the pattern matrix. This remarkable acute design has 9-, 10-, 11-, and 12-pointed stars, and is arguably the most complex non-systematic design that repeats upon the isometric grid from the plethora of such patterns throughout this ornamental tradition. This figure demonstrates how the underlying tessellation for this design places dodecagons at the vertices of the isometric grid (dashed lines), nonagons at the vertices of the dual hexagonal grid (dashed lines), decagons at the midpoints of the edges of the triangular cells, and hendecagons (11-sided) within the field of the polygonal matrix. These primary regular polygons allow for the introduction of the four varieties of local symmetry to the completed design: the 9-, 10-, 11- and 12-pointed 
stars. The four primary polygons are surrounded by a connective matrix of irregular pentagons and barrel hexagons. This masterpiece of geometric art was produced during the Seljuk Sultanate of Rum, and two examples are found within the architectural record: the carved stone ornament in the courtyard portal of the Seri Han near Avanos (1230-35), and the carved stone ornament of the entry to the mosque at the Karatay Han near Kayseri (1235-41). These contemporaneous examples are only $65 \mathrm{~km}$ apart, and are almost certainly the work of the same artist or atelier.

The beauty of non-systematic compound star patterns is, in large part, a direct consequence of their geometric sophistication. Indeed, this highly refined utilization of the polygonal technique is responsible for the creation of the most geometrically complex Islamic star patterns throughout the length and breadth of the Islamic world. As distinct from the less complex patterns created from one or another of the traditional design systems, the considerably more complex non-systematic designs are only possible to produce with the polygonal technique. Other design methodologies do not have the flexibility to work seamlessly with the diverse complexities associated with the multiple regions of local symmetry. While far less complex than the patterns that would soon follow, the non-systematic design in the northeast dome chamber of the Friday Mosque in Isfahan is the earliest known example a non-systematic geometric pattern.

\section{The Geometric Designs of the Northeast Dome Chamber}

The geometric designs within the northeast dome chamber are located within a series of eight blind arches: two placed in close proximity to one another at $90^{\circ}$ vertical orientation on each side of the corners within the square base of the chamber. ${ }^{10}$ These eight arches are populated with just seven distinct geometric patterns, with one of these being used in two of the eight arches. This duplication is a mystery, as it must be assumed that the originator of these seven patterns would have been fully capable of producing an eighth original design.

The pattern that was used twice within the eight recessed arches is the least complex of the seven designs (Fig. 25). This is a very simple, but highly effective geometric pattern that is easily created from the $6^{3}$ hexagonal grid. This grid is the least complex of the tessellations created from the system of regular polygons. Figure 10a demonstrates how this design places $30^{\circ}$ crossing pattern lines at the center points of each underlying hexagonal edge, and is hence categorized as an acute design. The acute design from the northeast dome chamber replaces the $30^{\circ}$ contact angles with $45^{\circ}$ crossing pattern lines, thereby slightly changing the proportions of the 6-pointed stars. It is somewhat surprising that acute design was not used more frequently within this ornamental tradition. Other Seljuk examples include one of the small blind arches in the upper muqarnas squinches of the Friday

\footnotetext{
${ }^{10}$ There are also a series of historically less important geometric patterns placed in the arch spandrels in the lower section of this chamber. Each of these is a comparatively simple and well-known design, and not part of this current discussion.
} 


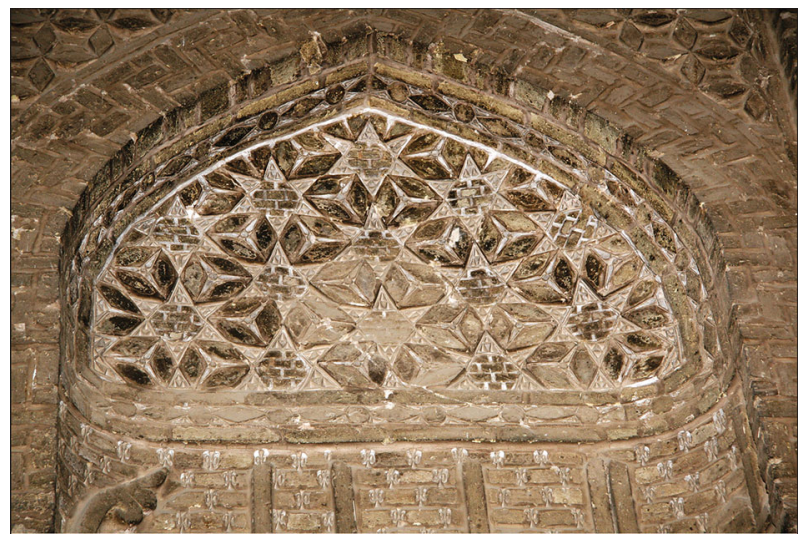

Fig. 25 An acute pattern with 6-pointed stars from the recessed arches in northeast dome chamber of the Friday Mosque at Isfahan

Mosque in Barsian, near Isfahan (1105), and the carved stucco intrados of an arch at the Friday Mosque at Sin, Iran (1134). A contemporaneous Fatimid example is from the portable wooden mihrab of the Sayyid Ruqayya Mashhad in Cairo (1133). ${ }^{11}$ A later Mamluk example is from a stone relief at the Imam al-Shafi'i mausoleum in Cairo (1211). While this example from the northeast domed chamber in Isfahan is the earliest known example of this acute pattern, other designs that can be created from the $6^{3}$ hexagonal grid were produced at an earlier date. Figure $10 \mathrm{~b}$ is the classic 3 -fold median pattern with $60^{\circ}$ crossing pattern lines that is created from this same underlying tessellation. This is one of the most widely used geometric patterns throughout Muslim cultures, and a few fine examples include: the Aljafería Palace in Zaragoza, Spain (second half of the eleventh century); the Mamluk window grilles of the Sultan Qala'un funerary complex in Cairo (1284-85); and the Ilkhanid mausoleum of Uljaytu in Sultaniya, Iran (1310-13). Figure 10c is another variety of median pattern with $90^{\circ}$ crossing pattern lines. This design is similarly ubiquitous, and a particularly impactful example from the Seljuk Sultanate of Rum is found at the Sultan Han near Aksaray (1229). Figure 10d is an obtuse patterns with $120^{\circ}$ crossing pattern lines. This is also very well known throughout Muslim cultures. The linear bands of this pattern are, in and of themselves, the 3.6.3.6 tessellation of triangles and hexagons, and it is somewhat disingenuous to the innovative brilliance of Muslim artists working within this tradition to assume that they would have required an underlying tessellation of hexagons to arrive at a design comprised of the 3.6.3.6 semi-regular grid. There are many 2-point patterns that can also be constructed from the simple hexagonal grid, four of which are represented in the lower portion of this figure. The pattern in Fig. 10e is uncommon and appears to have been used primarily in Persian miniature paintings. Figure $10 \mathrm{f}$ was used frequently throughout Muslim cultures, and a relatively early example from Seljuk Anatolia is from the Alaeddin mosque in Kırşehir, Turkey (1230). The design in

${ }^{11}$ Currently in the collection of the Islamic Museum in Cairo. 


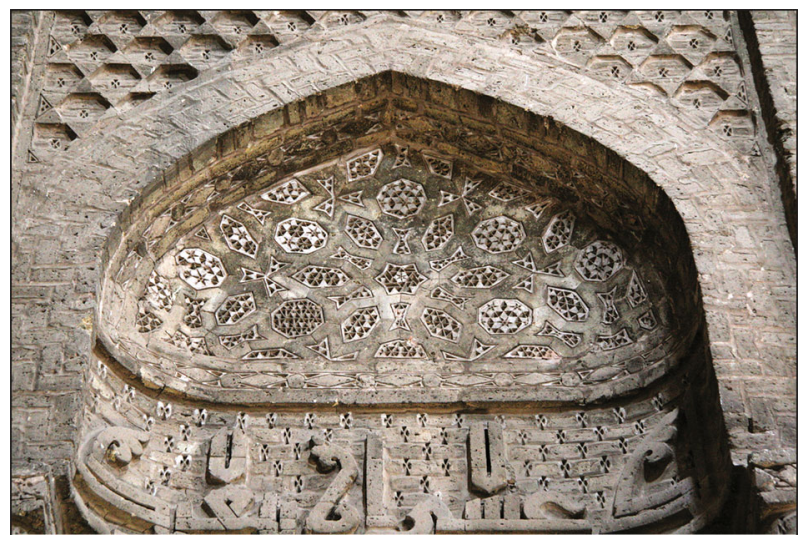

Fig. 26 An acute pattern comprised of 6-pointed stars and octagons from the recessed arches in the northeast dome chamber of the Friday Mosque at Isfahan

Fig. 10g was used at the Sabz Pushan outside Nishapur (960-85) (Fig. 1) and originates during the period of Samanid influence over this region. This design was also used on the eastern tomb tower at Kharraqan (1067-68). The pattern of superimposed hexagons in Fig. 10h was also used ubiquitously, and particularly early examples include an Umayyad marble grill from al-Andalus (tenth century), as well as by Ghurid artists at the Friday Mosque at Herat (1200).

The other design created from the system of regular polygons that is found within the recessed arches of the northeast dome chamber is characterized by a combination of 6-pointed stars and regular octagons within the pattern matrix (Fig. 26). This is the earliest known example of a design created with the distinctive ditrigonal module from the system of regular polygons. Figure 27 a shows the relationship between this design from the northeast dome chamber and its unusual underlying generative tessellation comprised of ditrigons and 6-pointed stars. The ditrigon is not a regular polygon, nor is the underlying 6-pointed star. As such, and strictly speaking, this design would not appear to qualify as part of the system of regular polygons. However, the underlying tessellation is, in and of itself, the same as the classic median pattern in Fig. 10c. Although somewhat tangential, because this design is derived from an underlying tessellation that is, in turn, derived from a tessellation that is part of the system of regular polygons, it is appropriate to regard this as part of this generative system. This is a very good example of the innovative freedom that artists experienced within a methodological framework that might otherwise appear constrained. Over time, the incorporation of ditrigonal elements into the underlying tessellations of patterns created from the system of regular polygons became an occasional feature of this design tradition. This pattern from the northeast dome chamber in Isfahan predates by some 80 years the next extant examples of patterns that employ ditrigonal modules at the above-referenced Ghurid ornaments of the minaret of Jam and the Shah-i Mashhad in Gargistan (Fig. 13b). This same underlying generative tessellation of ditrigons and 6-pointed stars was used in several later architectural settings to produce patterns that are very similar to 


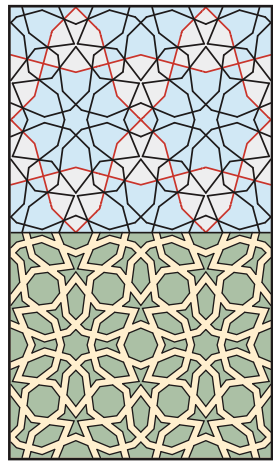

(a)

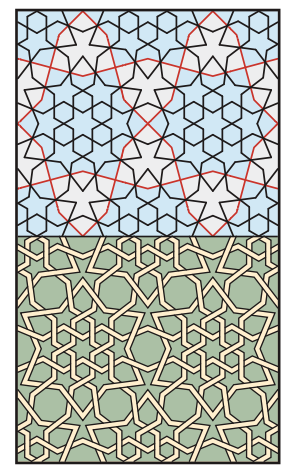

(b)

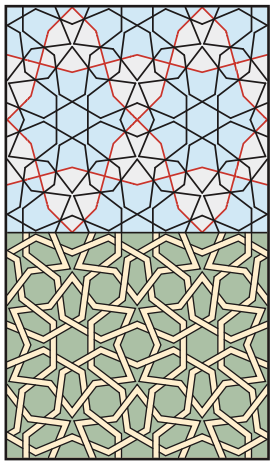

(c)

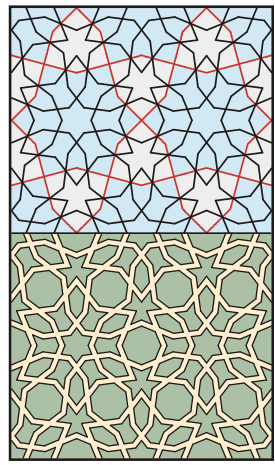

(d)

Fig. 27 The derivation of four historical acute designs created tangentially from the system of regular polygons. Figure 27a is the construction of the variation from the northeast dome chamber in Fig. 26

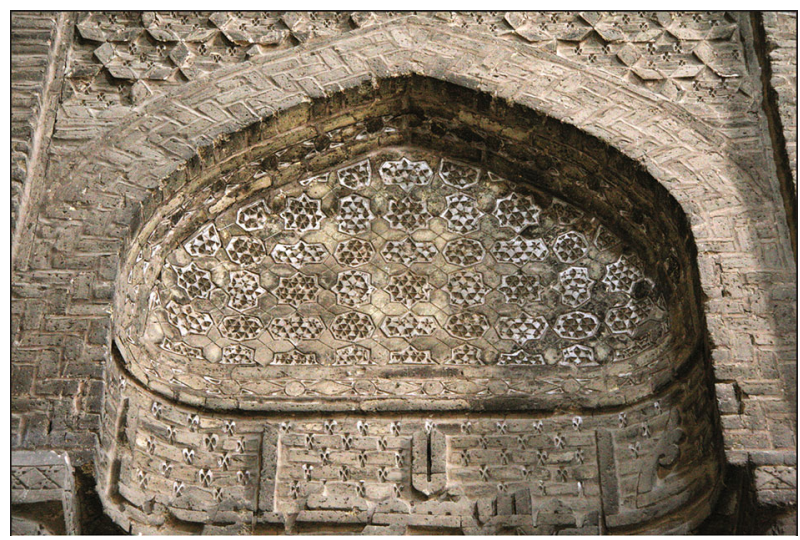

Fig. 28 An orthogonal pattern with 8-pointed stars and octagons from the recessed arches in the northeast dome chamber of the Friday Mosque at Isfahan

the ditrigonal design from Isfahan. Figure $27 \mathrm{~b}$ is from the mihrab of the Karatay madrasa in Antalya (1250), and Fig. 27c is from the Arslanhan mosque in Ankara (1289-90). Both of these were produced in Anatolia during the Seljuk Sultanate of Rum. Figure 27d is a Mamluk variation used in a window grille at the Tabarsiyya madrasa (1309) at the al-Azhar mosque in Cairo.

The orthogonal design with 8-pointed stars and octagons from the recessed arches of the northeast dome chamber (Fig. 28) is an interesting amalgam of two very simple 4-fold patterns derived from the underlying octagons and squares of the 4-fold system A. Figure 29a illustrates the underlying tessellation along with the applied median pattern lines, thereby placing 8-pointed stars into each underlying octagon. This is the classic star-and-cross design that was an already wellestablished design at the time this example was created. For example, this had previously been used at the No Gumbad mosque in Balkh, Afghanistan (800-50). 


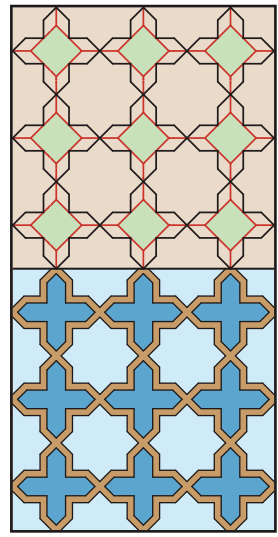

(a)

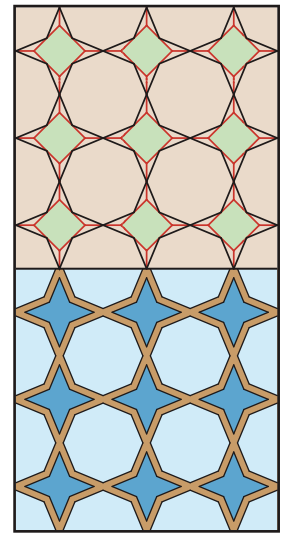

(b)

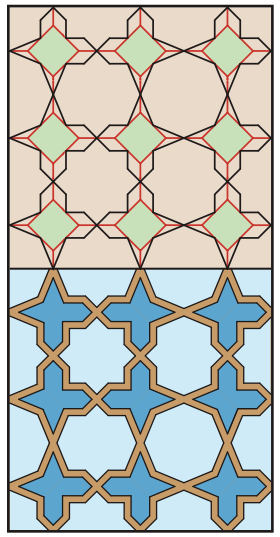

(c)

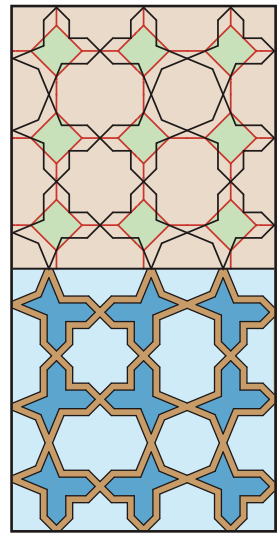

(d)

Fig. 29 Four designs produced from the $4.8^{2}$ tessellation of octagons and squares. Figure 20a is the standard median pattern, and Fig. 20b is the standard obtuse patterns. Figure 20c, d are amalgams of these two patterns. Figure 29d provides the derivation for the design in Fig. 28

Figure $29 \mathrm{~b}$ illustrates the same underlying tessellation, but with applied obtuse pattern lines. This places octagons within each underlying octagon. The resulting pattern is also well known to the historical record, and even pre-dates the advent of Islam. Both of these examples can alternatively be produced by simply placing the 8-pointed stars or the octagons in a point-to-point orthogonal assembly. The design in Fig. 29c is an amalgam of these two designs wherein 8-pointed stars and octagons are placed within alternating underlying octagonal cells. The resulting pattern would be awkward to produce in any other manner. However, a close inspection between this combined design with the photograph from the northeast dome chamber reveals dissimilitude in the proportions of the 12-sided shield shaped motifs, as well as differences in the relative size of the octagons. Figure $29 \mathrm{~d}$ demonstrates an adjustment to the applied pattern lines that provides for these differences. This is achieved by reducing the size of the octagons such that their extended lines intersect with the vertices of the underlying octagons rather than their midpoints. This simple procedure has the desired effect of reducing the octagons and elongating the 12 -sided shield elements, thereby providing a more balanced design. This is the only known example of this design within the historical record.

An interesting feature of this 4-fold example is in the textured treatment of the alternating polygonal cells that comprise the design (Fig. 28). This treatment introduces small scale carved relief patterns with 6-fold symmetry into the 8-pointed stars, octagons and the 12-sided shield elements. The fact that these three motifs do not have 6-fold symmetry creates a dynamic asymmetry that is bold and aesthetically pleasing. The use of small-scale carved stucco relief patterns, typically with 6-fold symmetry, was used frequently by Seljuk artists as a textured infill devise.

The geometric designs within the northeast dome chamber also include the three earliest extant patterns with 5-fold symmetry. This is highly significant in that these 


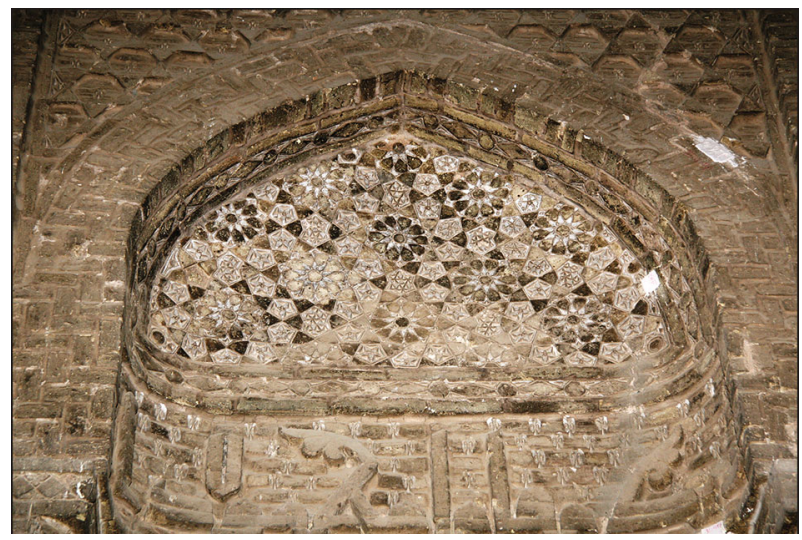

Fig. 30 The classic 5-fold obtuse pattern from the recessed arches in the northeast dome chamber of the Friday Mosque at Isfahan

are the first known examples of sophisticated 5-fold art ever produced by humankind. The 5-fold system of pattern generation is of particular significance to the history of Islamic art and architecture. Over time, this form of design spread throughout the Islamic world, receiving ongoing innovative attention and lasting popularity. Within a 100 years of the creation of the three 5-fold examples in the northeast dome chamber this variety of design was making full use of rhombic, rectangular and hexagonal repeat units.

The least complex of the three 5-fold patterns in the northeast dome chamber is the classic obtuse pattern that repeats upon a rhombic grid with $72^{\circ}$ and $108^{\circ}$ included angles (Fig. 30). This is the first known use of this highly popular design, and indeed, the four patterns represented in Fig. 19 that are created from the underlying tessellation responsible for this design were widely used by Muslim cultures. As we have seen within the 4-fold system A (Fig. 15), a single geometric design can sometimes be created from more than one underlying tessellation made up of differing modules from the same system. Figure 31 illustrates two methods for constructing the obtuse design from the northeast dome chamber. Figure $31 \mathrm{a}$ is the standard obtuse derivation with $108^{\circ}$ contact angles of the crossing pattern lines. Figure $31 \mathrm{~b}$ is an alternative derivation created from an underlying tessellation of decagons and concave hexagons, with the $72^{\circ}$ contact angles in the crossing pattern lines of the median pattern family. The generative modules in both these tessellations are all members of the 5-fold system. Figure 31c shows how these alternative formative grids are essentially duals of one another. While this design can be generated from either an obtuse or median pattern line application, the design itself is classified as an obtuse pattern. This is due to the stylistic characteristics of the pattern lines within the generative pentagonal module. As per Fig. 18, in acute patterns of this system, this module produces a 5-pointed star with $36^{\circ}$ crossing pattern lines; in median patterns, the generative modules produce 5-pointed stars with $72^{\circ}$ crossing pattern lines; and in obtuse patterns, this module produces crossing pattern lines with $108^{\circ}$ crossing pattern lines. The particular qualities of the 


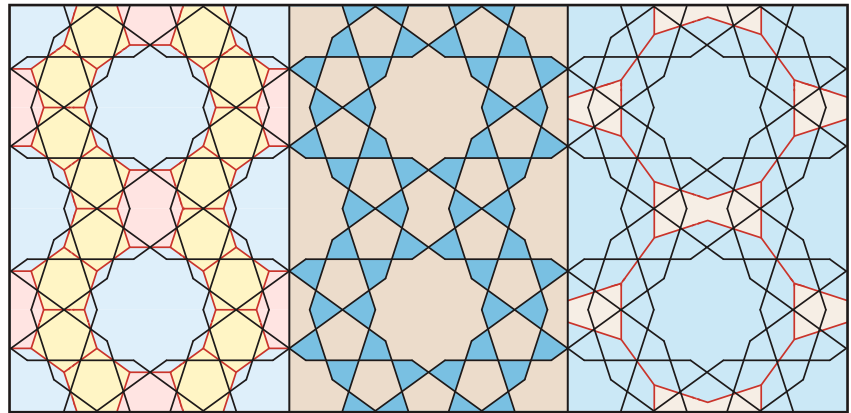

(a)

(b)

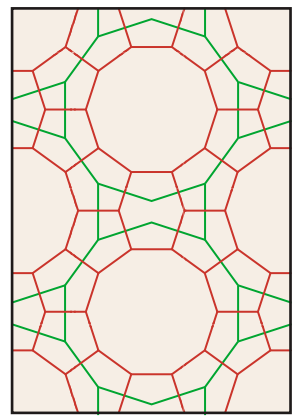

(c)

Fig. 31 Two configurations of underlying generative modules from the 5-fold system that will produce the classic 5-fold obtuse design from Fig. 30. Figure 31c demonstrates how these two generative tessellations have dual characteristics with one another

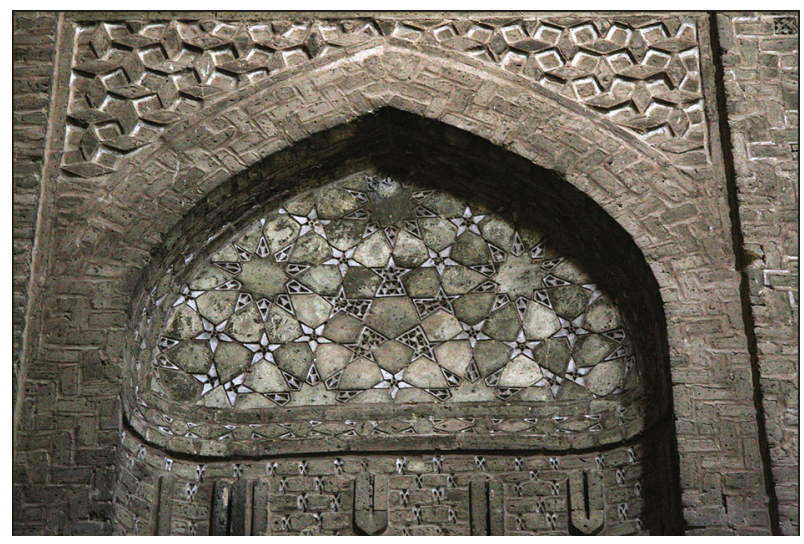

Fig. 32 A 5-fold acute hybrid pattern from the recessed arches in the northeast dome chamber of the Friday Mosque at Isfahan

2-point family are self-evident. Each of these methods of applying pattern lines creates designs with distinct stylistic characteristics that require classification for greater clarity in understanding the diversity of this ornamental tradition (Bonner 2016).

The second 5-fold design from the northeast dome chamber is considerably more complex in its geometric structure (Fig. 32). As demonstrated in Fig. 33, this acute design is remarkable in that it employs more than a single type of repetitive cell to make up the design contained within the recessed arch. The most obvious, due to its complete representation, is the large central pentagon, the base of which rests upon the horizontal spring line of the arch, with 10-pointed stars placed at each vertex. Attached to the four exposed edges of this pentagon are rhombi with $72^{\circ}$ and $108^{\circ}$ included angles. It is noteworthy that the pattern contained within just this rhombic region is the classic acute design as per Fig. 19, and the occurrence of this rhombic 


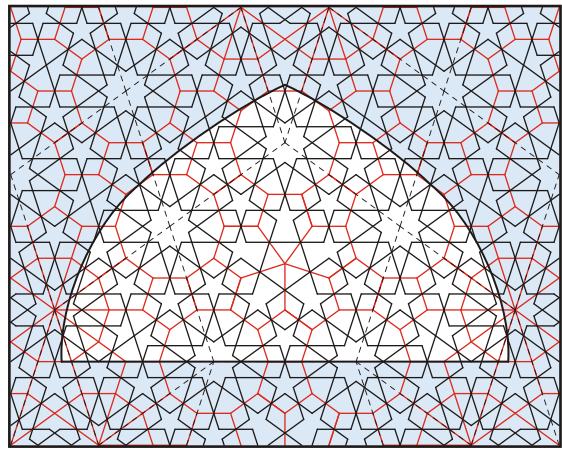

(a)

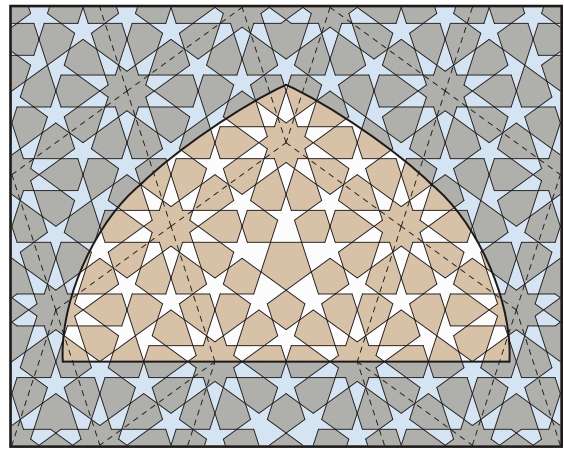

(b)

Fig. 33 The construction of the 5-fold acute hybrid design from Fig. 32 that employs more than one variety of repetitive cell

motif is the earliest known example of this classic acute pattern, albeit not as a continuous surface coverage in its own right. The pattern within the large central pentagon is noteworthy on two counts: it is the earliest example of a 5-fold design with rotation symmetry; and it is the earliest 5 -fold pattern to employ the motif of a central pentagon surrounded by five 9-sided flattened star motifs that are derived from the five underlying irregular pentagons in Fig. 33a. The acute pattern within the recessed arch is the earliest known historical example of a hybrid design composed of two or more independent repetitive cells. This method of achieving greater 5-fold design complexity was used subsequently in several Anatolian locations during the Seljuk Sultanate of Rum, including: a median design from the Huand Hatun in Kayseri (1237); an obtuse design from the Izzeddin Kaykavus hospital and mausoleum in Sivas (1217); and two acute designs from the Karatay Han near Kayseri (1235-41). In later centuries Marinid artists in Morocco and Mamluk artists in Egypt created several examples of this variety of design. A still later 5-fold hybrid design of particularly fine quality is from a Mughal stone mosaic panel on the façade of the I'timad al-Daula in Agra, India (1622-28) (Bonner 2016).

It is important to note that in analyzing this hybrid design from the northeast dome chamber a certain amount of conjecture has been used to fill the two-dimensional plane beyond the obvious central pentagon and immediately adjacent rhombic cells. The artist who created this remarkable design may have used a different combination of repetitive cells in the peripheral regions that extend beyond the pentagon and rhombi, and are not seen in the completed design as defined by the arch. Indeed, the artist did not have to work with a continuous two-dimensional coverage at all, and may have just worked with the three rhombic cells on each side of the central pentagonal cell. This would have been enough to extrapolate the complete design. One way or another, an artist clever enough to have developed the combined use of the pentagon and rhombi with $72^{\circ}$ and $108^{\circ}$ included angles used in this design would have likely also discovered the need of the further rhombus with $36^{\circ}$ and $144^{\circ}$ included angles for full two-dimensional coverage. These more acute rhombi are implicit within this construction (for example, the upper point of the 10-pointed star 


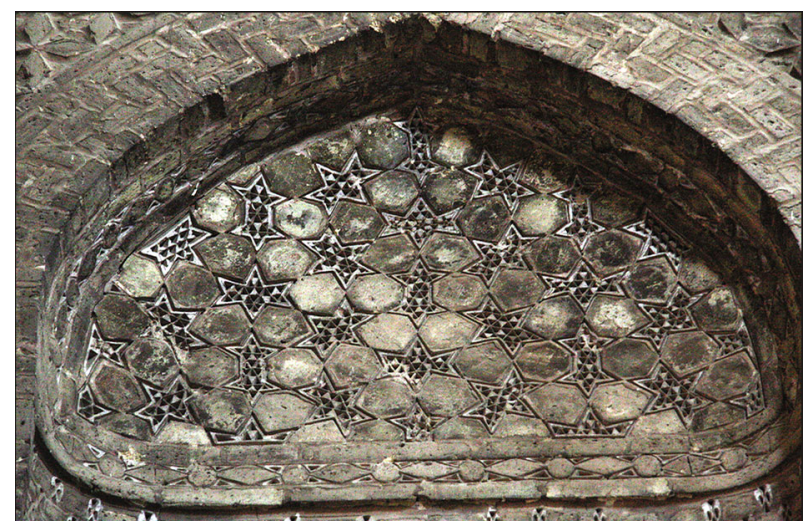

Fig. 34 An acute pattern created from the 7-fold system in one of the recessed arches in the northeast dome chamber of the Friday Mosque at Isfahan

at the apex of the arch), and had the artist who devised this design been aware of the more acute rhombus, this individual may have been the first to discover the contiguous tiling potential of these two "Penrose rhombi." Although these rhombi have the ability for non-periodic application, or even aperiodic tiling with Penrose's matching rules, the historical examples of Islamic geometric designs are invariably periodic with translation symmetry, and there is no evidence that Muslim artists were aware of the non-periodic potential of this design methodology. ${ }^{12}$

As with the historical significance of the two 5-fold examples cited above, one of the recessed arches that surround the cupola within the northeast dome chamber contains the earliest example of a 7-fold pattern known to this ornamental tradition (Fig. 34). The underlying tessellation that creates this Seljuk pattern is comprised of just two polygonal modules, both of which are hexagons. The lower panel in Fig. 35 demonstrates how the proportions of both these hexagons are easily derived from the regular heptagon. These two polygonal modules, along with their associated pattern lines, are part of a set that can be arranged into countless tessellations, thereby providing a distinct systematic approach to producing 7-fold designs (Fig. 20). At this early stage of development, it is impossible to know to what extent artists were aware of the systematic tessellating potential of these two generative hexagons along with their heptagonal source. However, in light of the fact that the

\footnotetext{
${ }^{12}$ The occurrence of quasi-crystalline geometric structures among historical examples of Islamic geometric art has recently been purported in several publications (Lu and Steinhardt 2007; Makovicky and Makovicky 2011; Al Ajlouni 2012), and has generally been accepted as fact among the interested public. However, without exception, all cited examples repeat upon a unit cell with translation symmetry - regardless of the amount of geometric information contained within each unit cell. This is the very antithesis of quasi-periodicity. The inflation and deflation within the design and the underlying generative polygonal sub-structure of the cited examples does not change the fact that the meta-design invariably repeats within a unit cell. As such, the inflation and deflation that is present in the cited two-level designs is indicative of self-similarity rather than quasi-crystallinity (Bonner 2003; Cromwell 2009). That said, the multi-level design methodologies employed by Muslim artists of the past have been used by several contemporary artists (for example, Jean-Marc Castera, Marc Pelletier, and the author of this paper) to create recursive geometric patterns that meet the criteria for true quasi-periodicity.
} 

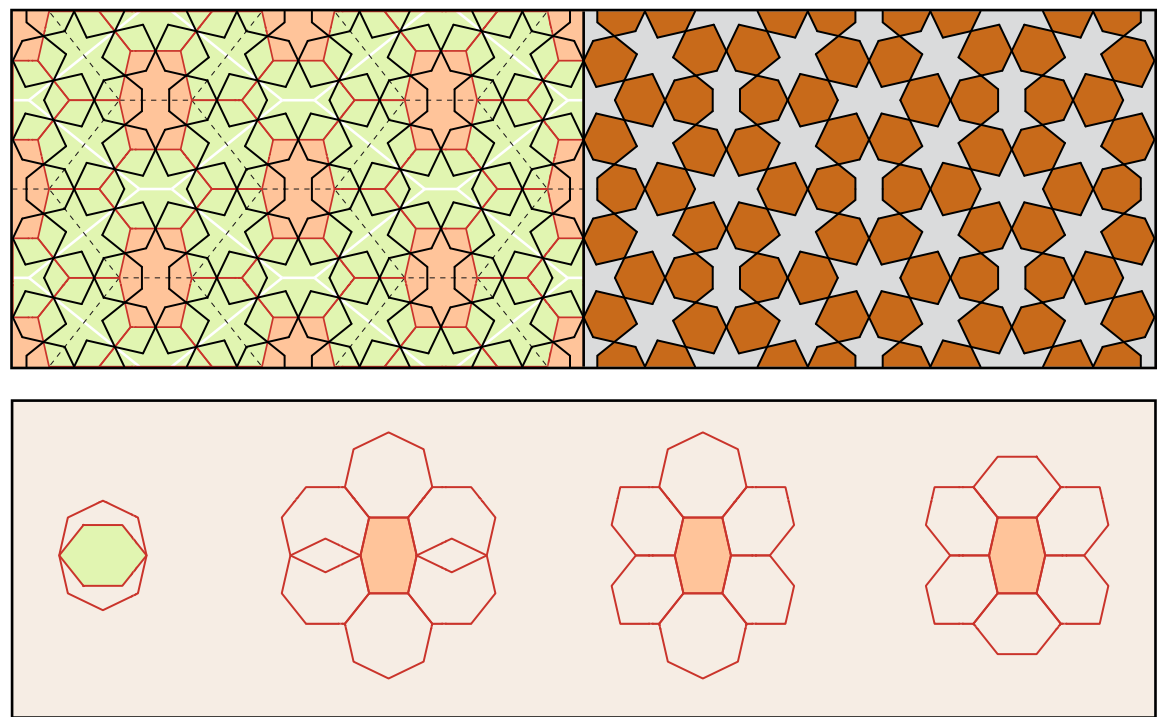

Fig. 35 The construction of the 7-fold pattern in Fig. 34. This design has two varieties of irregular hexagonal repeat unites (dashed lines). The lower part of this figure demonstrates how the two types of underlying generative hexagonal module are both easily constructed from the heptagon

two 5-fold examples from this same chamber are distinctly systematic, it can be plausibly assumed that the same artist would have also known the systematic nature of these 7-fold polygonal modules. The upper panel in Fig. 35 illustrates the application of acute pattern lines onto the underlying tessellation. This figure also shows the two varieties of hexagonal repeat unit (dashed lines) that provide the translation symmetry for this design. The crossing pattern lines of this acute design have $51.4286^{\circ}$ contact angles. This is determined from the inherent geometry of the heptagon, although this polygonal module is not used within this underlying tessellation. The absence of regular polygons, such as heptagons or tetradecagons (14 sides), within the underlying tessellation, and the concomitant absence of star forms with radial symmetry within the generated pattern, places this example into the 7-fold field pattern category.

The only other historical example of this 7-fold pattern is, significantly, an illustration from the anonymous Persian treatise On Similar and Complementary Interlocking Figures [Anonymous: fol. 192r]. ${ }^{13}$ Remarkably, this illustrated example includes the underlying generative tessellation, along with accompanying step-by-step instructions for its construction. The depiction of generative schema is extremely unusual within this tradition, and along with the Topkapi scroll, this illustration is hence an important primary source for the historicity of the polygonal technique. It is interesting that the depiction of this 7-fold pattern is the only

\footnotetext{
13 I am indebted to Professor Jan Hogendijk in the Mathematics Department at Utrecht University for bringing to my attention the fact that the 7-fold pattern in the northeast dome chamber is identical to the example from the anonymous Persian treatise.
} 
example from this treatise that includes the underlying generative tessellation; almost all of the other geometric patterns being point-joining constructions. Scholars have suggested possible origins for this treatise that range between the eleventh and thirteenth centuries, with apparent revisions introduced during the Timurid period when the Paris manuscript was copied (Necipoğlu 1995; Özdural 1996). More recent scholarship has narrowed the date of origin to circa 1300, with modifications introduced during the middle of the fifteenth century (Necipoğlu 2015). The multiple associations with the patterns in the northeast dome chamber suggest that this treatise was significantly influenced by these architectural examples, thereby indicating Isfahan, at least in part, as a likely place of origin (Necipoğlu 2015; Bonner 2016). The anonymous Persian treatise includes two other patterns with 7-pointed stars. However, one is an orthogonal design that places 7-pointed stars along the edges of the square repeat, and the other is a compound pattern that includes 8-pointed stars. While both these designs have 7-fold local symmetry, their overall geometric structures are not the product of 7-fold symmetry, and neither is produced from the 7-fold system.

The Seljuks excelled in creating complex non-systematic geometric patterns from a relatively early date. As mentioned above, this variety of geometric pattern will frequently include seemingly irreconcilable combinations of star forms, typically placed within a standard triangular, square or regular hexagonal repetitive schema. Non-systematic designs also occasionally employ repeat units that are rectangles, non-regular hexagons and, more rarely, radial segments of a circle, polygon or star (Bonner 2016). The tradition of especially complex non-systematic patterns with compound local symmetries reached full maturity under the auspices of the Seljuk Sultanate of Rum in Anatolia and the Mamluks in Egypt during the thirteenth and fourteenth centuries; but the antecedents and earliest examples of this variety of design were established during the late eleventh and twelfth centuries by the Seljuks in Khurasan and Persia and their Atabeg subordinates to the west. In seeking an understanding of the historical development of particularly complex patterns with multiple regions of differentiated local symmetry, it is important to take into account the tremendous loss of early monuments in Transoxiana, Khurasan, Persia and Iraq through natural disasters, neglect, and especially the Mongol destruction during the thirteenth century. Of particular significance to the early history of this variety of geometric pattern is the Friday Mosque at Barsian near Isfahan, Iran (1105). The mihrab of this mosque is framed by a very interesting non-systematic design comprised of 7- and 9-pointed stars that repeats upon an elongated hexagonal grid (Bonner 2016). This is an early example of a geometric design that fills the two-dimensional plane by virtue of a geometric ploy whereby the numeric quality of the alternating star forms are one numerical step above and below the number of stellate points of a more common and convenient design with a singular repeating star form; such as 6-, 8-, 10-, or 12-pointed stars. In this way, the fact that 6-pointed stars will conveniently repeat is an indication that a compound pattern can be created that employs both 5- and 7-pointed stars. The pattern from the mihrab of the Friday Mosque at Barsian applies this principle of adjacent numbers to the repetitive convenience of the octagon; indicating the potential for a successful, if considerably less geometrically convenient, repetitive pattern with 7 , 
and 9-pointed stars. It is impossible to know whether Muslim artists of the past were aware of this as a design principle per se, or whether the creation of such patterns comprised of 5- and 7-pointed stars, 7- and 9-pointed stars, 9- and 11-pointed stars, or 11- and 13-pointed stars was purely serendipitous. Other examples of particularly complex non-systematic geometric patterns are included among the arches of the muqarnas hood in the mihrab from the Friday Mosque at Barsian. These include a design with 12- and 16-pointed stars, a pattern comprised of 13-pointed stars, and another with 11- and 12-pointed stars (Bonner 2016). The limited amount of geometric information contained in the two latter examples is insufficient to conclusively determine either the repetitive structure or the complete underlying generative tessellation, and it is possible that the artist distributed 11-, 12-, and 13-pointed stars into these two small arched regions without their being part of a broader repetitive structure.

Other Seljuk examples of non-systematic compound patterns include a design with 5-, 6- and 7-pointed stars in the arch spandrels at the top of each exterior wall of the decagonal façade on the Gunbad-i Qubad in Maragha, Iran (1196-97); and an adjacent pattern with 8- and 9-pointed stars that frames the muqarnas arch at the top of each exterior wall of the façade of the same building. It is interesting to note what would appear to be the deliberate decision by the artist to juxtapose the pattern with 5-, 6-, and 7-pointed stars with a pattern comprised of 8- and 9-pointed stars. The use of two adjacent complex designs that have continuous sequenced numeric qualities is very unusual, and emphasizes the playfulness and geometric facility of the artist.

The earliest known example of non-systematic pattern making is from one of the recessed arches that surround the northeast dome chamber of the Friday Mosque at Isfahan, and although not nearly as complex as such patterns were soon to become (also under Seljuk patronage), this example is nonetheless very beautiful (Fig. 36). As illustrated in Fig. 37a, the underlying generative tessellation for this design places edge-to-edge regular pentagons upon each triangular edge of the isometric

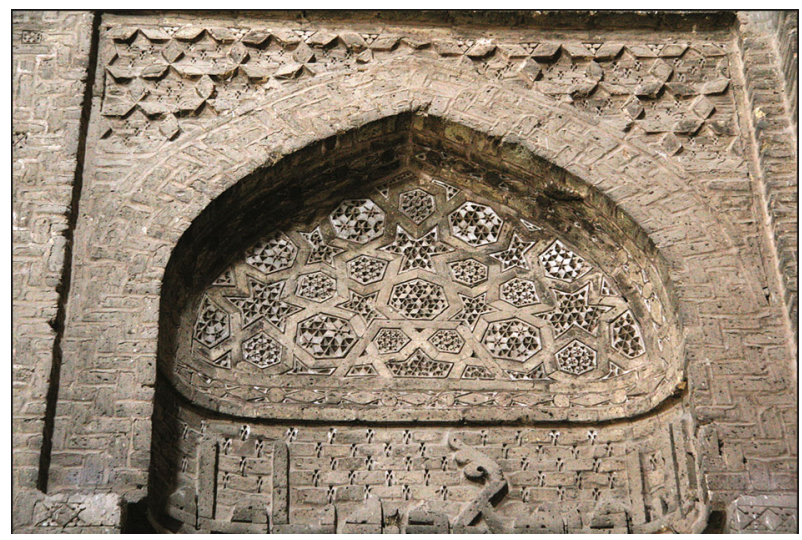

Fig. 36 The non-systematic acute pattern from the recessed arches in the northeast dome chamber of the Friday Mosque at Isfahan 


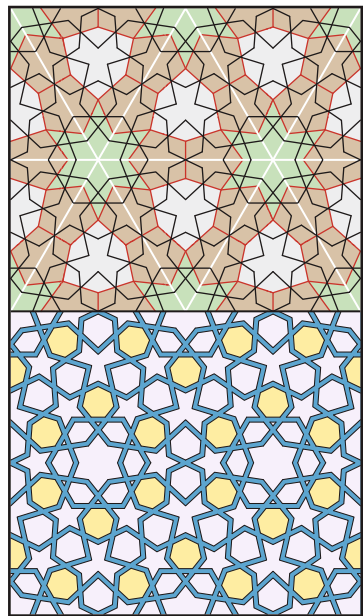

(a)

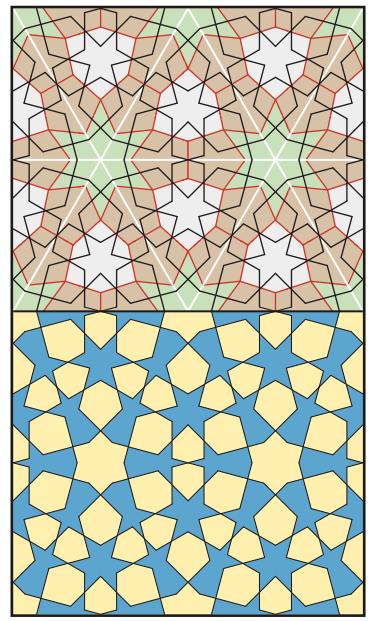

(b)

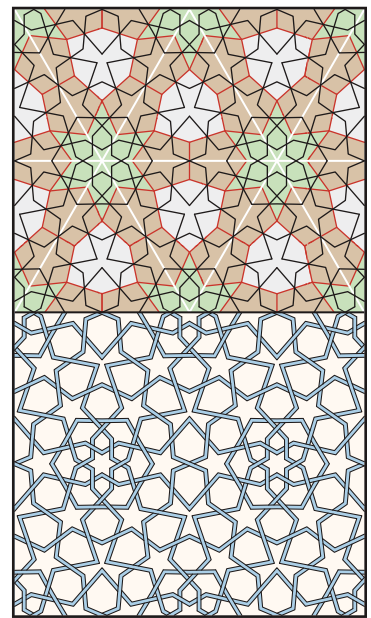

(c)

Fig. 37 Three historical designs variations created from the same non-systematic underlying tessellation of regular pentagons, ditrigons and 6-pointed stars. Figure 37a illustrates the derivation of the example from Fig. 36

grid. This creates two interstice elements that are specific to this pentagonal arrangement: a 6-pointed star at the vertices of the isometric grid, and a ditrigon at the centers of each triangular repeat unit. This very successful Seljuk design is from the acute family. The contact angles of the crossing pattern lines that produce the 5-pointed stars are arbitrarily derived from the heptagon rather than the pentagon, and their angle and precise placement along the underlying polygonal edges allows for the creation of regular heptagons (white) as background elements within the overall pattern matrix. These heptagonal background elements are a remarkable feature of this design, and thematically tie this design to the nearby 7-fold design in Fig. 35. Also of particular interest is the pattern treatment within the central ditrigonal element. As shown in Fig. 37a, the acute pattern lines within the ditrigonal interstice regions are similar to those in the designs of Fig. 27, but with slightly different proportions. Figure $37 \mathrm{~b}$ illustrates a variation of this nonsystematic acute pattern that, like the 7-fold pattern cited above, is likewise illustrated in the anonymous Persian treatise On Similar and Complementary Interlocking Figures [Anonymous: fol. 193r]. Figure 37c represents a third version of this non-systematic design that was created by Zangid artists for the Nur al-Din Bimaristan in Damascus (1154).

The fact that the 7-fold design cited above, and the equally uncommon nonsystematic pattern from the recessed arches are both represented in the Persian treatise On Similar and Complementary Interlocking Figures is yet more evidence for the strong possibility of there being a direct association between this manuscript and the architectural ornament of this chamber of the Friday Mosque in Isfahan. 


\section{The Domical Geometric Design in the Northeast Dome Chamber}

Among the greatest achievements of Seljuk geometric artists was the pioneering application of geometric patterns onto the surfaces of domes. Subsequent Muslim dynasties followed in this design convention, and exceptional examples with greater complexity were produced by the Zangids and Ayyubids in Syria, the Nasrid and Christian Mudéjar artists in Spain, the Mamluks in Egypt, the Muzaffarids and Timurids in Persia and Central Asia, and the Mughals in India. By comparison, the early work of the Seljuks may appear simplistic. Indeed, the elaborate ribbed vault of the Sultan Sanjar mausoleum in Merv, Turkmenistan (1157), for all its boldness and beauty, does not exhibit particular geometric complexity. This design employs an 8-pointed star at the apex, and the design unfolds upon an 8-fold radial division of the interior domical surface. The interior ornament of the earlier Seljuk dome in the Friday Mosque at Golpayegan (1105-18) similarly places an 8-pointed star at the apex, and 8-fold radial segmentation of the surface. Surrounding the central 8-pointed star are eight 7-pointed stars, followed downward by eight 5-pointed stars, and culminating at the periphery with a ring of half 8-pointed stars. ${ }^{14}$ This stellar matrix, while still rather simple when compared to the non-Euclidean work of subsequent generations of Muslim artists, has all the visual characteristics of a pattern that was produced using the methodology of the polygonal technique. The dome at Golpayegan is the earliest extant example in Islamic architecture of the application of a geometric design onto the surface of a dome using radial gore segments as the repetitive device. Over time, this became the historically preferred repetitive methodology for applying both geometric and floral patterns onto domical surfaces. However, Seljuk artists also pioneered an alternative method of applying geometric patterns onto domical surfaces that uses polyhedral geometry as the repetitive strategy for controlled spherical surface coverage (Brotherton 2005; and Bonner 2016).

The earliest known use of polyhedra for creating a non-Euclidean geometric design is from the northeast dome chamber of the Friday Mosque at Isfahan (Fig. 38). As demonstrated in Fig. 39, this magnificent dome is remarkable in that it is decorated with a 2-point pattern derived from the underlying geometry of the dodecahedron. The dodecahedron is one of the five Platonic solids, and is comprised of twelve regular pentagonal faces. The application of 2-point pattern lines onto each underlying domical pentagon, and the central placement of a pentagon upon the apex of the dome create the distinctive 5-fold rotational symmetry of this dome. The pentagonal faces of the dodecahedron are spherically projected onto the curved surface of the dome, and it is important to point out that the use of the dodecahedron would ordinarily produce a hemispherical dome. While the applied 2-point pattern is unquestionably derived from the dodecahedron, this otherwise spherical surface has been modified to incorporate the characteristic ascendancy of traditional Persian pointed domes wherein the curvature rises to an apex. The use of underlying generative pentagons aligns this example with patterns produced from the 5 -fold

\footnotetext{
14 Images of the radial gore segmented geometric dome in the Friday Mosque at Golpayegan are difficult to find. For a good example, see (Hoag 1975: 201).
} 


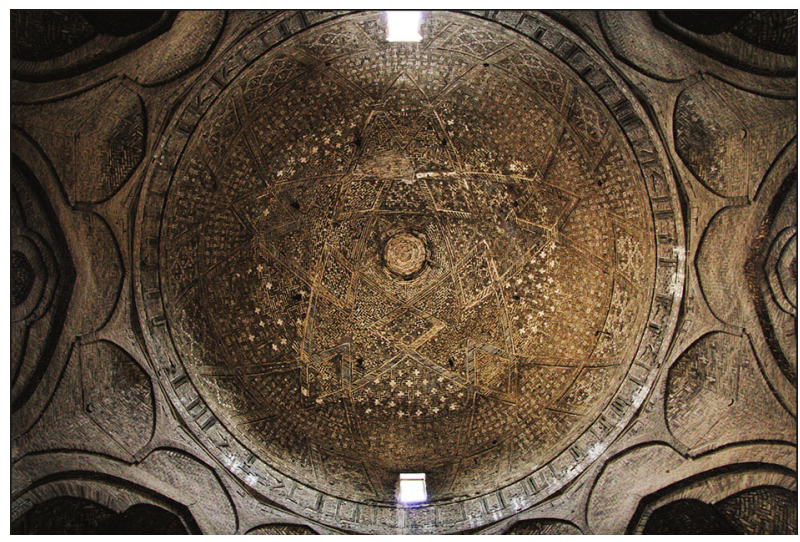

Fig. 38 The dodecahedral 2-point pattern on the dome from the northeast dome chamber of the Friday Mosque at Isfahan

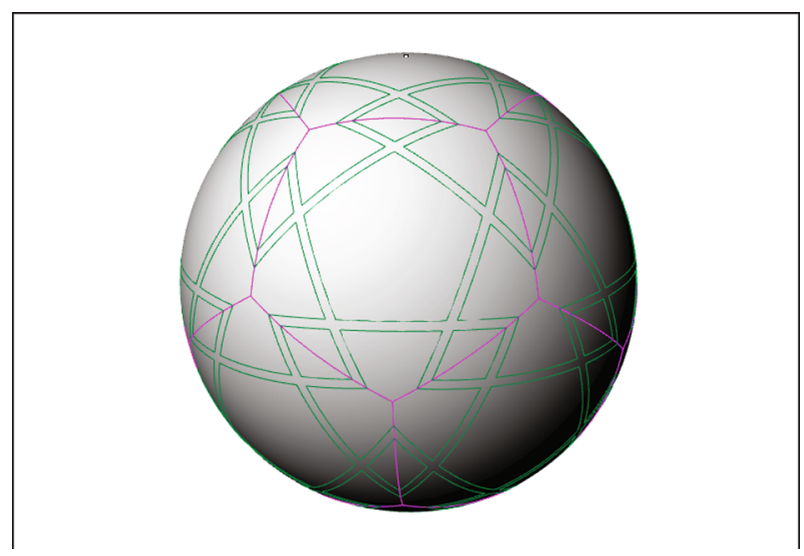

Fig. 39 The 2-point pattern as applied to a spherical projection of the dodecahedron as per the 5-fold design of the dome in the northeast dome chamber

system: the difference being that the two-dimensional plane requires at least one other element from the 5-fold system to accompany the generative pentagons, while the dodecahedron is a spherical configuration of just pentagons. There appear to be only two other known examples of domical dodecahedral ornament. One of these is also a 2-point pattern that is placed on a projecting hemispherical stone detail in the arch spandrel of the entry portal at the Sahib Ata mosque in Konya (1258). Other than the fact that this example is a true hemisphere, the main difference between this example from the Seljuk Sultanate of Rum and the earlier example from Isfahan is that the pattern lines are given a curvilinear treatment. The other historical dodecahedral ornament is also from the Seljuk Sultanate of Rum. This is a median pattern applied to the projecting stone hemisphere in the mihrab of the Huand Hatun complex in Kayseri (1237). 
The greater complexity of later polyhedral geometric patterns is a product of the greater complexity of the underlying polyhedral foundation. Almost all of these later examples employ Archimedean solids as their repetitive schema (Bonner 2016). The median design in the quarter-dome hood of the mihrab arch at the Lower Maqam Ibrahim in the citadel of Aleppo (1168) is directly derived from the truncated icosahedron (soccer ball) with pentagonal and hexagonal faces. This is a masterpiece of Zangid woodworking. Artists working during the Seljuk Sultanate of Rum produced a design on a projecting stone hemisphere that is based upon the geometry of the truncated cube and employs an acute pattern with 8-pointed stars and regular hexagons. This is located in the arch spandrel of the portal at the Susuz Han in Susuzköy, Turkey (1246). The Ayyubid mihrab hood of the al-Sharafiyah madrasa in Aleppo (before 1205) uses an acute pattern made up of 8- and 5-pointed stars that is based upon the geometry of the octahedron. This is signed by 'Abd alSalâh Abû Bakr. A more complex acute design was produced by the Ayyubid artist Abu al-Husayn bin Muhammad al-Harrani 'Abd Allah bin Ahmed al-Najjar for the hood of the wooden mihrab (1245-46) of the Halawiyya mosque and madrasa in Aleppo. This also employs the octahedron as its repetitive structure, but uses 5-, 8and 9-pointed stars within its pattern matrix. Perhaps the most complex geometric pattern constructed from polyhedral geometry is from an anonymous Mamluk mausoleum in the Nouri district of Tripoli, Lebanon. The repetitive structure of this example is the cuboctahedron, comprised of eight triangular faces and six square faces, and the 2-point pattern matrix includes both 8- and 10-pointed stars. Emil Makovicky has detailed the eccentric polyhedral geometry of a dome in one of the porticos in the Court of Lions at the Alhambra in Granada, Spain (c. 1354-91) (Makovicky 2000). This exceptional Nasrid wooden dome is unusual in that it does not adhere to the polyhedral geometry of either the Platonic or Archimedean solids, although the upper portion of the dome follows the geometry of the snub cube. Rather, it is essentially an octacapped-truncated octahedron with two varieties of non-equilateral triangle. The geometric pattern of this remarkable hemispherical dome places 11-pointed stars at the vertices of each spherically projected polygonal face. Two very beautiful non-architectural examples of spherical geometric ornament based on polyhedra are found in an Afghan brass incense globe (circa 1200), ${ }^{15}$ and the ornate enameled pommel of a jineta sword that belonged to Sultan Muhammad XII, the last Nasrid ruler of Granada. ${ }^{16}$ The Afghan incense globe is a simple spherical expression of the icosidodecahedron wherein interweaving widened great circles transect the vertices of this Archimedean polyhedra comprised of twelve pentagons and twenty triangles. The geometric pattern on the jineta sword pommel is based upon the geometry of the truncated cube comprised of six octagons and eight triangles. Placing 8-pointed stars into the octagonal components of the truncated cube produces a spherical median pattern that is directly analogous to the two-dimensional use of octagons and squares for creating the classic star-and-cross

\footnotetext{
15 Exhibited anonymously in the inaugural exhibition of the Islamic Art Gallery of the King Faisal Center for Research and Islamic Studies in Riyadh, Saudi Arabia, 1985. Published in the exhibition catalogue: The Unity of Islamic Art. London: King Faisal Foundation, pl. 87.

${ }^{16}$ Museo del Ejército, Madrid, 24.902.
} 
design (Fig. 29a). It is worth noting that the ornament on both the hilt and scabbard of this sword employ the standard two-dimensional star-and-cross design with precisely the same aesthetic treatment as the spherical pommel. The artist responsible for this sword clearly understood the analogous relationship between these two designs.

Several prominent scholars have suggested the possible involvement of 'Umar Khayyam (1048-1131) in the construction of the northeast dome chamber of the Friday Mosque at Isfahan (Grabar 1990; Özdural 1998; Hogendijk 2012). This hypothesis is based upon the fact that 'Umar Khayyam was living in Isfahan at the time of this dome's construction, and enjoyed the scientific patronage of Taj alMulk, who commissioned the dome. As a leading mathematician of his time, 'Umar Khayyam would have been familiar with polyhedral geometry and spherical projection: a requisite of the designer of this important monument. ${ }^{17}$ If true, and especially in light of the methodological relationship between the 2-point geometric pattern on the dome and those employed within the eight recessed arches of the domed chamber, 'Umar Khayyam may have been highly significant not just as a mathematician and poet, but also to the historical development of the polygonal technique: the design methodology most responsible for the mature style of Islamic geometric design. Such a confluence of mathematics, poetry and geometric art is a delight to the imagination.

\section{Conclusion}

The 5-fold domical geometric design in the northeast dome chamber, together with the seven neighboring geometric patterns placed within the eight recessed arches, represent a remarkable advance in the historical development of this ornamental tradition. The many 'first occurrences' present in these eight geometric designs opened the door to the fully mature geometric design practices that soon followed. As such, the importance of these patterns to the history of Islamic geometric art is paramount. The design innovations that were first introduced during the construction of this building include: the first use of underlying ditrigonal modules within the system of regular polygons; the first patterns with 5-fold symmetry created from the 5-fold system; the first occurrence of a 5-fold obtuse pattern; the earliest occurrence of the classic 5-fold obtuse design; the earliest 5-fold acute design; the earliest 5-fold 2-point design; the first hybrid pattern (in this case 5-fold) that utilizes more than a single repetitive cell; the first pattern with 7-fold symmetry created from the 7-fold system; the earliest example of a non-systematic design; and the first occurrence of a domical geometric pattern that uses a polyhedron as its repetitive schema. What is more, the three 5-fold designs and the one 7-fold pattern are the first occurrences of sophisticated examples of these two types of symmetry known to have been produced by humankind the world over. It is doubtful that any

\footnotetext{
17 The works of the mathematician and astronomer, Abu al-Wafa Buzjani (940-998), would have been familiar to 'Umar Khayyam, and of especial relevance to this discussion would have been his work on right angled spherical triangles and spherical trigonometry.
} 
other single room, or even individual building within the totality of Islamic architecture had such a profound significance to the historical development of Islamic geometric art.

Acknowledgments The text, illustrations and photographs in this paper are excerpted from the author's soon-to-be-published book titled Islamic Geometric Patterns: their Historical Development and Traditional Methods of Construction (Bonner 2016). The multiple portions of this book that have been combined into this paper have been edited in the interests of both space and continuity. All photographs of the northeast dome chamber (Figs. 6, 25, 26, 28, 30, 32, 34, 36, 38) included in this paper are by the kind permission of the photographer and copyright holder Tom Goris in the Netherlands. Figure 5 of the minaret of Daulatabad outside Balkh, Afghanistan, and Fig. 3 of the carved Ghaznavid panel from the Kabul Museum are included by the kind permission of the photographer and copyright holder Thalia Kennedy. Figure 4 of the Taq-i Bust in Afghanistan is included by the kind permission of the photographer and copyright holder Bernard O'Kane. Figure 2 from the three mausolea in Uzgen, Kyrgystan is included by the kind permission of the photographer and copyright holder Igor Goncharov. The Sabz Pushan stucco panel in Fig. 1 is reproduced by permission of the Metropolitan Museum of Art: Rogers Fund, 1940 (40.170.442) Image (c) The Metropolitan Museum of Art.

\section{References}

Al Ajlouni, Rima A. 2012. The global long-range order of quasi-periodic patterns in Islamic Architecture. Acta Crystallographica. Section A, Foundations of crystallography A68: 235-243

Anonymous. No date. Fi tadakhul al-ashkal al-mutashabiha aw al-mutawafiqa (On Similar and Complimentary Interlocking Figures). Bibliothèque Nationale de France, Paris, Ms. Persan 169, fols. 180r-199r.

Bonner, Jay F. 2000. Islamic Geometric Pattern: Their Historical Development and Traditional Methods of Derivation. Washington D. C.: Library of Congress copyright TXu000981014 / 2000-08-21.

Bonner, Jay. F. 2003. Three Traditions of Self-Similarity in Fourteenth and Fifteenth Century Islamic Geometric Ornament. In: Meeting Alhambra: ISAMA Bridges 2003 Conference Proceedings, 1-12. University of Granada.

Bonner, Jay. F. and Marc Pelletier. 2012. A 7-Fold System for Creating Islamic Geometric Patterns, Part 1: Historical Antecedents. In: Bridges Towson: Mathematics, Music, Art, Architecture, Culture, annual Conference Proceedings, 141-148. Maryland: Tessellation Publishing.

Bonner, Jay F. and Marc Pelletier. 2012. A 7-Fold System for Creating Islamic Geometric Patterns, Part 2: Contemporary Expression. In. Bridges Towson: Mathematics, Music, Art, Architecture, Culture, annual Conference Proceedings, 149-156. Maryland: Tessellation Publishing.

Bonner, Jay F. 2016. Islamic Geometric Patterns: Their Historical Development and Traditional Methods of Construction. New York City: Springer

Brotherton, Richard. 2005. Polyhedral Geometry, Syrian Stereotomy, Umbrella Honorifics, and Cairene Paradigm Shift in Stone Dome Construction Methodology. The Mamluk Domes of Egypt: A workshop sponsored by the Aka Khan Program for Islamic Architecture at MIT.

Cromwell, Peter. 2009. The Search for Quasi-Periodicity in Islamic 5-fold Ornament. The Mathematical Intelligencer 31(1): 36-56

Cromwell, Peter. 2010. Islamic Geometric Design from the Topkapi Scroll II: a Modular Design System. Journal of Mathematics and the Arts 4(3): 119-136

Cromwell, Peter. 2012. Analysis of a Multilayered Geometric Pattern from the Friday Mosque in Yazd. Journal of Mathematics and the Arts 6(4): 159-168

Grabar, Oleg. 1990. The Great Mosque of Isfahan. New York University Press: 85.

Hankin, E. H. 1905. On Some Discoveries of the Methods of Design Employed in Mohammedan Art. London: Journal of the Society of Arts 53: 461-477.

Hankin, E. H. 1925a. The Drawing of Geometric Patterns in Saracenic Art. Calcutta: Memoirs of the Archeological Survey of India 15.

Hankin, E. H. 1925b. Examples of Methods of Drawing Geometrical Arabesque Patterns. London: Mathematical Gazette 12: 371-373 
Hankin, E. H. 1934. Some Difficult Saracenic Designs II: A Pattern Containing Seven-Rayed StarsMathematical Gazette 18: 165-168

Hankin, E. H. 1936. Some Difficult Saracenic Designs III. Mathematical Gazette 20: 318-319

Hoag, John D. 1975. Islamic Architecture. New York City: Abrams, Inc

Hogendijk, Jan. 2012. Mathematics and Geometric Ornament in the Medieval Islamic World. Newsletter of the European Mathematical Society 86: 37-43

Kaplan Craig 2002. Computer Graphics and Geometric Ornamental Design. Ph.D. thesis, University of Washington.

Kaplan, Craig. and David H. Salesin. 2004. Islamic Star Patterns in Absolute Geometry. ACM Transactions on Graphics 23 (2): 97-119

Kaplan Craig 2005. Islamic Star Patterns from Polygons in Contact; Graphics Interface, annual conference proceedings: $177-186$.

Lu, Peter J. and Paul J. Steinhardt. 2007. Decagonal and Quasi-Crystalline Tilings in Medieval Islamic Architecture. Science 315: 1106-1110

Makovicky, Emil. 1992. 800-year-old pentagonal tiling from Maragha, Iran, and the new varieties of aperiodic tiling it inspired. In: Fivefold Symmetry, ed. Istvan Hargittai, 67-86. Singapore-London: World Scientific

Makovicky, Emil. 1998. Decagonal Patterns in the Islamic Ornamental Art of Spain and Morocco. Boletín de la Sociedad Española de Mineralogía 21: 107-127

Makovicky, Emil. 2000. Structure of the domes of pavilions in the Patio del los Leones, the Alhambra: a distorted octacapped truncated octahedron. Boletín de la Sociedad Española de Mineralogía 23: 37-41

Makovicky, Emil and Nicolette M. Makovicky. 2011. The first find of dodecagonal quasiperiodic tiling in historical Islamic architecture. Journal of Applied Crystallography 44: 569-573

Necipoğlu, Gülru. 1995. The Topkapi Scroll - Geometry and Ornament in Islamic Architecture. Santa Monica, CA: Getty Center for the History of Art and the Humanities

Necipoğlu, Gülru ed. 2015. The Arts of Ornamental Geometry: A Persian Compendium on Similar or Complementary Interlocking Figures (A Volume Commemorating Alpay Özdural). Leiden, Boston: Brill.

Özdural, Alpay. 1996. On Interlocking Similar or Corresponding Figures and Ornamental Patterns of Cubic Equations. Muqarnas 13: 191-211

Özdural, Alpay. 1998. A mathematical sonata for architecture. Technology and Culture 39: 699-715

Sarhangi, Reza. 2012. Interlocking Star Polygons in Persian Architecture: The Special Case of the Decagram in Mosaic Designs. Nexus Network Journal 14(2): 345-372

Wulff, Hans E. 1966. The Traditional Crafts of Persia. Cambridge, MA: MIT Press

Jay Francis Bonner is an independent scholar of Islamic geometric design. He received his MDes in this field from the Royal College of Art, London, in 1983. He has lectured and given design seminars widely, including venues at Duke University; the Rhode Island School of Design; the University of Washington; the Bridges Conferences at the University of Granada and Towson University; the University of San Francisco; the Lorentz Center at Leiden University; the Pécs-Ars Geometrica Conference in Hungary; the Academie des Arts Traditionnels in Morocco; the Istanbul Design Center in Turkey; and the Historians of Islamic Art Association Conference in Toronto. He is also a design consultant specializing in Islamic architectural ornament. He has worked on many buildings, including: the expansion of the Grand Mosque in Mecca; the expansion of the Prophet's Mosque in Medina; the Abraj Al-Bait Clock Tower in Mecca; the International Medical Center in Jeddah; the Tomb of Sheikh Hujwiri in Lahore; the New Senate House in Rawalpindi; and the Ismaili Centre in London. He provided the ornamental design for the marble minbar for the Kaaba in Mecca. He is also the ornamental design consultant for a large research facility dedicated to the study of higher mathematics in Northern California designed in the style of the Alhambra. 